\title{
Review of the caddisfly genus Tagalopsyche with the description of new species and a related new genus (Trichoptera: Leptoceridae: Mystacidini)
}

\author{
RALPH W. HOLZENTHAL ${ }^{1} \&$ TROND ANDERSEN ${ }^{2}$ \\ ${ }^{1}$ Department of Entomology, University of Minnesota, 1980 Folwell Ave., Room 219, St. Paul, Minnesota, 55108, U.S.A. \\ E-mail: holze001@umn.edu \\ ${ }^{2}$ The Natural History Collection, Bergen Museum, University of Bergen, Muséplass 3, N-5020 Bergen, Norway. \\ E-mail: trond.andersen@zmb.uib.no
}

\section{Table of contents}

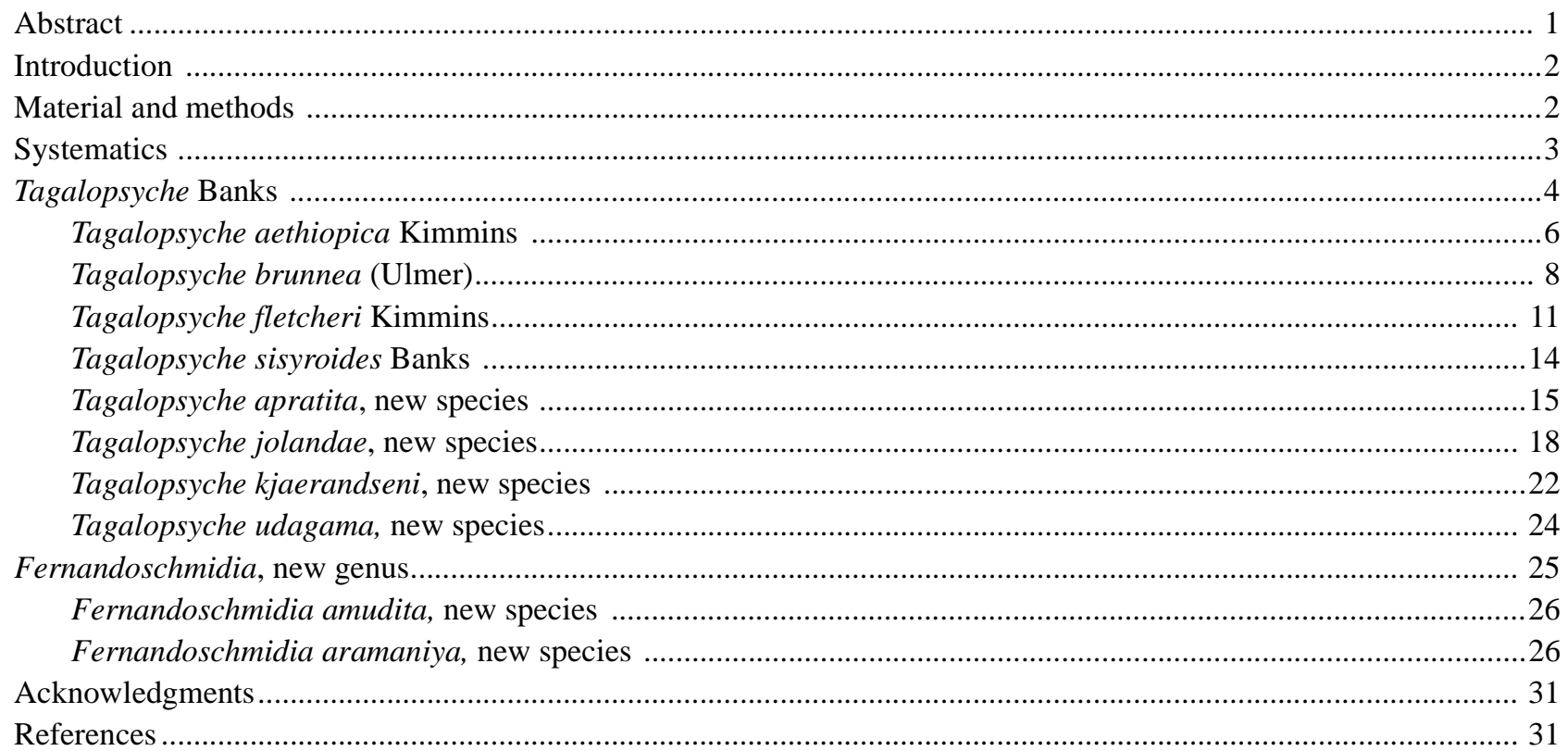

\begin{abstract}
The long-horned caddisfly genus Tagalopsyche Banks, 1913 (Leptoceridae: Mystacidini) is reviewed and 4 new species are described and illustrated: T. apratita, new species (India), T. jolandae, new species (Brunei, Malaysia), T. kjaerandseni, new species (Ghana), and T. udagama, new species (India, Sri Lanka). The 4 previously described species are redescribed and illustrated: T. aethiopica Kimmins, 1963a (Ethiopia), T. brunnea (Ulmer, 1905) (Indonesia), T. fletcheri Kimmins, 1963b (India), and T. sisyroides Banks, 1913 (Indonesia, Philippines). A related new genus, Fernandoschmidia, new genus, and 2 new species, $F$. amudita, new species, and $F$. aramaniya, new species, from India are described and illustrated. The phylogenetic position of the new genus is assessed; it is sister to a clade formed by Tagalopsyche and Mystacides Berthold, 1827, the only other genus in the Mystacidini.
\end{abstract}

Key words: Trichoptera, Leptoceridae, Tagalopsyche, Fernandoschmidia, new species, new genus, Mystacidini, taxonomy, Afrotropical, Oriental, revision, male genitalia 


\section{Introduction}

In the course of our investigations into the long-horned caddisflies, or Leptoceridae, of the western Afrotropical Region (Andersen and Holzenthal 2001, 2002a, b), a new species of Tagalopsyche was discovered from material collected during a project on the freshwater insects of Ghana, conducted by the junior author and colleagues from the University of Bergen, Norway, and the University of Ghana, Accra. The discovery of this new species prompted a review of the genus in its entirety, including the description of additional new species from India, Sri Lanka, Brunei, and Malaysia from the collections of the National Museum of Natural History, Smithsonian Institution, and the National Natural History Museum, Leiden, The Netherlands. Additional material, borrowed from the Canadian National Collection, Ottawa, yielded 2 new species belonging to a new genus of Mystacidini. Males and known females of these new taxa are described and illustrated below and the phylogenetic placement of the new genus within the leptocerid tribe Mystacidini is discussed.

The long-horned caddisfly genus Tagalopsyche was erected by Banks (1913) and contains 4 described species from the Afrotropical and Oriental Regions: T. aethiopica Kimmins, 1963a from Ethiopia, T. brunnea (Ulmer, 1905) from Java, T. fletcheri Kimmins, 1963b from India, and T. sisyroides Banks, 1913 from the Philippines. Morse (1981) placed Tagalopsyche together with Mystacides Berthold in the tribe Mystacidini Burmeister, based on one synapomorphy: ventral apex of segment IX of the male genitalia produced posteriorly. Tagalopsyche can be easily separated from Mystacides by the venation of the forewings, having fork I stalked, a comparatively short discoidal cell, and the anastomosis straight or only slightly oblique. Tagalopsyche also lacks the notch in the costal margin of the forewing typical of Mystacides, and the apex of the wing is not deflexed.

Little seems to be known about the biology of the species. Ulmer (1955) described pupae of T. sisyroides, taken in the outlet of Lake Ranau on southern Sumatra. At the outlet, the river was 60-80 m wide and $0.5 \mathrm{~m}$ deep (Ulmer 1957). Adults have been taken close to both lakes and rivers. Lake Ranau is situated at an altitude of $540 \mathrm{~m}$, while T. fletcheri was taken above $2000 \mathrm{~m}$ altitude in India (Kimmins 1963b). Tagalopsyche kjaerandseni, new species, was taken close to streams and small rivers in southeastern Ghana; the holotype was taken in a light trap close to a small, slow-flowing river at an altitude of $270 \mathrm{~m}$ (Andersen and Kjærandsen 2001).

\section{Material and methods}

Methods used for preparation of specimens followed those discussed by Holzenthal and Andersen (2004) and Blahnik and Holzenthal (2004). Genitalia were cleared in either $12.5 \%$ potassium hydroxide at room temperature for 6-12 hours, or in $85 \%$ lactic acid heated to $125^{\circ} \mathrm{C}$ for about 30 minutes. Pencil drawings of genitalic structures were made by use of a drawing tube on an Olympus BX41 compound microscope. Wings and thoracic structures were examined and drawn under an Olympus SZX12 stereomicroscope. Final illustrations of wings, head, thoracic structures, and genitalia were rendered in Adobe Illustrator ${ }^{\circledR}$. The interpretation of genitalic structures and terminology follows Morse and Yang (2002). Holotypes of the new species and other material examined are deposited in the collections of the University of Minnesota Insect Collection, St. Paul, Minnesota, USA (UMSP), the National Museum of Natural History, Smithsonian Institution, Washington, D.C., USA (NMNH), the Natural History Museum, London, England (NHM), the National Museum of Natural History, Leiden, The Netherlands (RMNH), the Canadian National Collection, Ottawa, Canada (CNC), the Natural History Collections, Bergen Museum, University of Bergen, Norway (ZMBN), and the Zoologische Staatsinstitut und Zoologisches Museum, Hamburg, Germany (ZSZMH).

The material borrowed from the Canadian National Collection contained 3 series of specimens collected by the late Dr. Fernand Schmid in India during the late 1950s and early 1960s. This material was indicated by Schmid as new species of Tagalopsyche and bears type labels and new names; however, these names were 
never published. We here assign one of these new species to Tagalopsyche and use the name applied to it by Schmid, but under our authorship. The other 2 new species are assigned to a new genus, named in honor of Schmid, using his new species names, but again under our authorship.

\section{Systematics}

Morse (1981) established monophyly for the Mystacidini and its 2 included genera, Mystacides and Tagalopsyche, based on the produced apex of sternum IX in the male genitalia. Morse and Yang (2002) inferred monophyly for Mystacides based on the following 7 synapomorphies: 1) head, thorax, and forewings dark brown or black; 2) absence of foretibial spurs; 3) forewing costal margin with subapical notch; 4) forewing fork I sessile; 5) forewing anastomosis obliquely aligned; 6) apex of forewing deflected mesad along anastomosis in resting insect; and 7) male phallobase with compressed anterodorsal flange of phallic shield. Morse (1981) inferred a sister group relationship between Mystacidini and Setodini based on the formation of a ventral phallic strip to brace the phallobase against the base of the fused inferior appendages. The genus Mystacides currently contains 19 species and was last reviewed by Morse and Yang (2002).

Tagalopsyche shares with Mystacides the posteriorly produced apex of sternum IX, which may be deeply (Fig. 9C) or slightly excised (Fig. 10C), or nearly truncate (Fig. 3C), although it is usually shorter and broader basally than the homologous structure in Mystacides. In addition, intimately associated with the posterior extension of sternum IX is a sclerotized, darkly pigmented, often rugose, generally triangular structure that extends dorsad between the bases of the inferior appendages (Figs. 3A, D, 9A, D, 13A, D). This additional development of the posterior extension of sternum IX is synapomorphic for Tagalopsyche. The shape and structure of the phallus is also synapomorphic for the genus. The phallus is short and compact, lacks parameres, and is abruptly and strongly curved ventrad apically (Fig. 3E, 7E). In addition, the apical face bears heavily sclerotized lateral flanges that are often produced dorsolaterally (Fig. 7F). The female genitalia are very similar to those of Mystacides, with slender preanal appendages and very large, spatulate lamellae (Figs. 4, 8); there appear to be no differences in the female genitalia to distinguish the 2 genera.

Tagalopsyche shares none of the venational syapomorphies listed by Morse and Yang (2002) for Mystacides. In Tagalopsyche, the forewing costal margin is entire and without a notch, forewing fork I bears a short stalk, the apex of the wing is not deflected, and the crossveins forming the anastomosis, while somewhat aligned, are not strongly oblique (Figs. 2A, 12A). In addition, the male phallobase lacks the compressed anterodorsal flange of the phallic shield, but has a basoventral flange that articulates with the base of the fused inferior appendages (Figs. 3A, 5A); this character is plesiomorphic for Tagalopsyche as it is homologous to the character used by Morse (1981) to define Mystacidini + Setodini. On the other hand, as in Mystacides, at least 1 species of Tagalopsyche also lacks foretibial spurs and several species are dark brown; these characters are here interpreted to be homoplastic within the tribe Mystacidini and not synapomorphic for Mystacides.

Two new species from India fit neither the definition of Mystacides nor Tagalopsyche and are here assigned to a NEW GENUS, Fernandoschmidia. The new genus shares with Mystacides and Tagalopsyche the posterior extension of sternum IX typical for members of Mystacidini (Figs. 17C, 19C), but it lacks the additional complex sclerotization of the dorsal part of this region seen in Tagalopsyche; in Fernandoschmidia, this region is entirely membranous (Figs. 17D, 19D). In Fernandoschmidia, the posterior margin of segment IX is extended as a pair of widely separated digitate processes (Figs. 17C, 19C). The phallic apparatus of the new genus is more primitive than found in either Mystacides or Tagalopsyche in that it is elongate, with clearly defined phallobase and phallicata as well as a pair of prominent articulated parameres (Figs. 17E, 19E). In both new species, the parameres bear a series of thick spines along their lengths and apically; the presence of these spines on the parameres is considered synapomorphic for the new genus. In addition, ventrolaterally on each side of the phallobase is a ridge-like flange that articulates with the dorsolateral corner of 
the basal region of the inferior appendage (Figs. 19A, 19E). This character is a novel modification of the ventral sclerotized brace of the phallobase more generally distributed in the clade Mystacidini + Setodini as discussed by Morse (1981). There is also a dorsomedial keel on the phallicata in both new species of Fernandoschmidia (Figs. 17E, 19E). These characters of the phallic apparatus are considered to be synapomorphic for the new genus. Finally, the inferior appendages of the 2 new species of Fernandoschmidia are much enlarged basally, with a flange-like sclerotized ridge ventrolaterally (best seen in caudal view) and abruptly narrowed, bifid apical halves (Figs. 17A, D, 19A, D); this structure of the inferior appendages may also be synapomorphic for the new genus. Wing venation of $F$. aramaniya, new species, is very similar to that of species of Tagalopsyche, without any of the synapomorphies listed by Morse and Yang (2002) for Mystacides (Fig. 18).

Within the Mystacidini, Fernandoschmidia seems to be the most primitive genus based on the retention of distinct phallobase, phallicata, and parameres in the phallic apparatus. The reduction and fusion of the phallobase and phallicata unites Mystacides and Tagalopsyche as sister genera.

\section{Tagalopsyche Banks}

Type species: Tagalopsyche sisyroides Banks, 1913, monotypic.

Tagalopsyche Banks, 1913: 177; 1916: 213. -Ulmer 1930: 404, 468, 492 [diagnosis, key]; 1951: 411, 417; 1955: 508, 511 [larva, pupa]. -Kimmins 1963a: 150.

Adult (Figs. 1-2). Length of forewing: male 5.5-8.5 mm, female 5.5-9.0 mm. Eye size normal to slightly enlarged (Kimmins 1963a, fig. 79). Antennae long, 2-3X length of forewing in male; scape large, subspherical. Maxillary palps long, heavily setose, segment 1 shortest, segments $2-5$ subequal. Labial palps much shorter, segment 3 longest. Anteromesal setal wart of head large, oval; anterolateral setal warts small, oval; posterolateral setal warts elongate oval. Tibial spurs $0,2,2$ or 1,2,2; foretibial spur, if present, very small. Forewing narrow to broad, apex broadly to acutely rounded; with sparse to dense, short decumbent hairs on membrane, and with conspicuous erect setae along veins; coloration variable, from light brown with cream colored hairs to dark brown with scattered small patches or spots of white hairs. Forks I and V present in both wings; in forewing, thyridal cell 1.5 to nearly 3 times as long as discoidal cell, fork I with short stalk; forewing anastomosis straight or slightly oblique, veins not contiguous; hind wing with stem of Rs degenerate in some species; fork V long.

Male genitalia. Abdominal segment IX annular, setose, anterior and posterior margins generally parallel; tergum IX short to long, shortest at insertion of preanal appendages; sternum IX extended posteriorly, entire, shallowly or deeply excised apically, apicolateral corners generally rugose; posterior process of segment IX extended dorsad to form heavily sclerotized, ovate to triangular, generally rugose projection. Preanal appendages oblong, heavily setose. Inferior appendages spatulate, setose, apex directed mesad; mesolateral surface with setose ridge or processes, basoventrally and mesobasally with seta bearing processes. Tergum X saddleshaped, dorsolaterally with short protuberances; in dorsal view apex entire or trifid. Phallic apparatus short, compact; phallobase tubular, apparently fused with phallicata; basoventrally with sclerotized flange apparently articulating with base of fused inferior appendages; phallicata strongly down turned apically, with heavily sclerotized lateral flanges, dorsolateral corners projecting; parameres absent; phallotremal sclerite not discernable.

Female genitalia. Segment IX short. Tergum X triangular; in dorsal view rounded or triangular; basoventrally generally with papillate processes. Preanal appendage digitate, setose. Lamellae very large, constricted basally, directed ventrad, surfaces setose. Basolateral edges of gonopod plate produced into flanges, surface with fine striations. Spermathecal sclerite complex, in ventral view broadly oval to rectangular, laterally with semimembranous flanges, medially with key-hole shaped sclerite. 

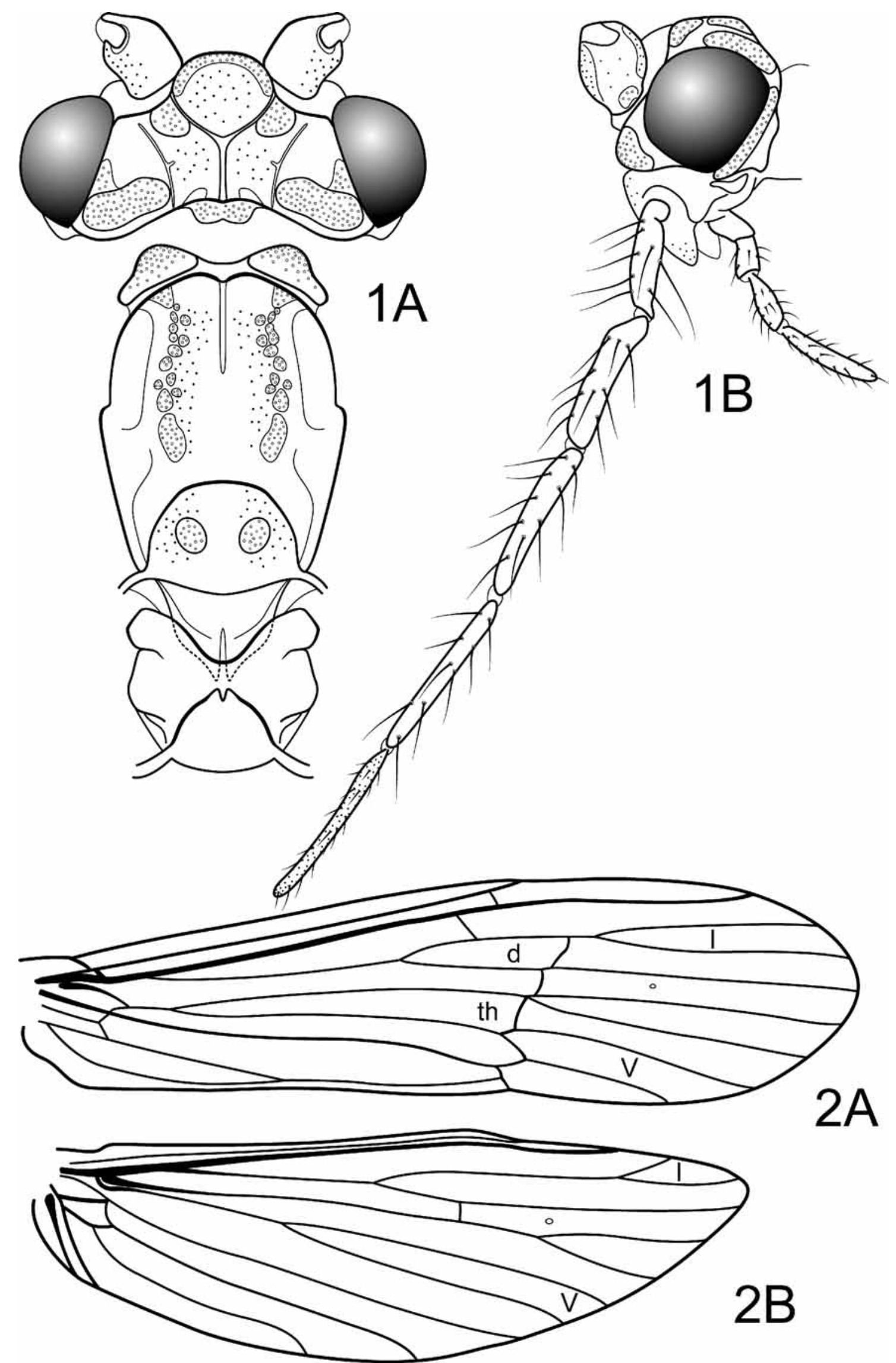

FIGURE 1-2. Tagalopsyche kjaerandseni, new species. 1. Adult: A-head and thorax, dorsal; B-head, left lateral. 2. Wings: A-forewing; B-hind wing. 


\section{Tagalopsyche aethiopica Kimmins}

Figs. 3-4

Tagalopsyche aethiopica Kimmins, 1963a: 149, figs. 79-86 [Type: Ethiopia, Lake Awasa, 6.xi.1960 (A. Tjønneland), male, NHM].

This species, 1 of only 2 members of the genus thus far known from Africa, is recognized most easily by the broadly spatulate shape and relative simplicity of the inferior appendage. In this regard, it is unlike the other African species, T. kjaerandseni, new species, and any of the Oriental species.

Adult. Length of forewing: male $8.0-8.3 \mathrm{~mm}(\mathrm{n}=3)$, female $8.1 \mathrm{~mm}(\mathrm{n}=2)$. Color light brown, with small patches of darker brown and cream hairs alternating along longitudinal wing veins.

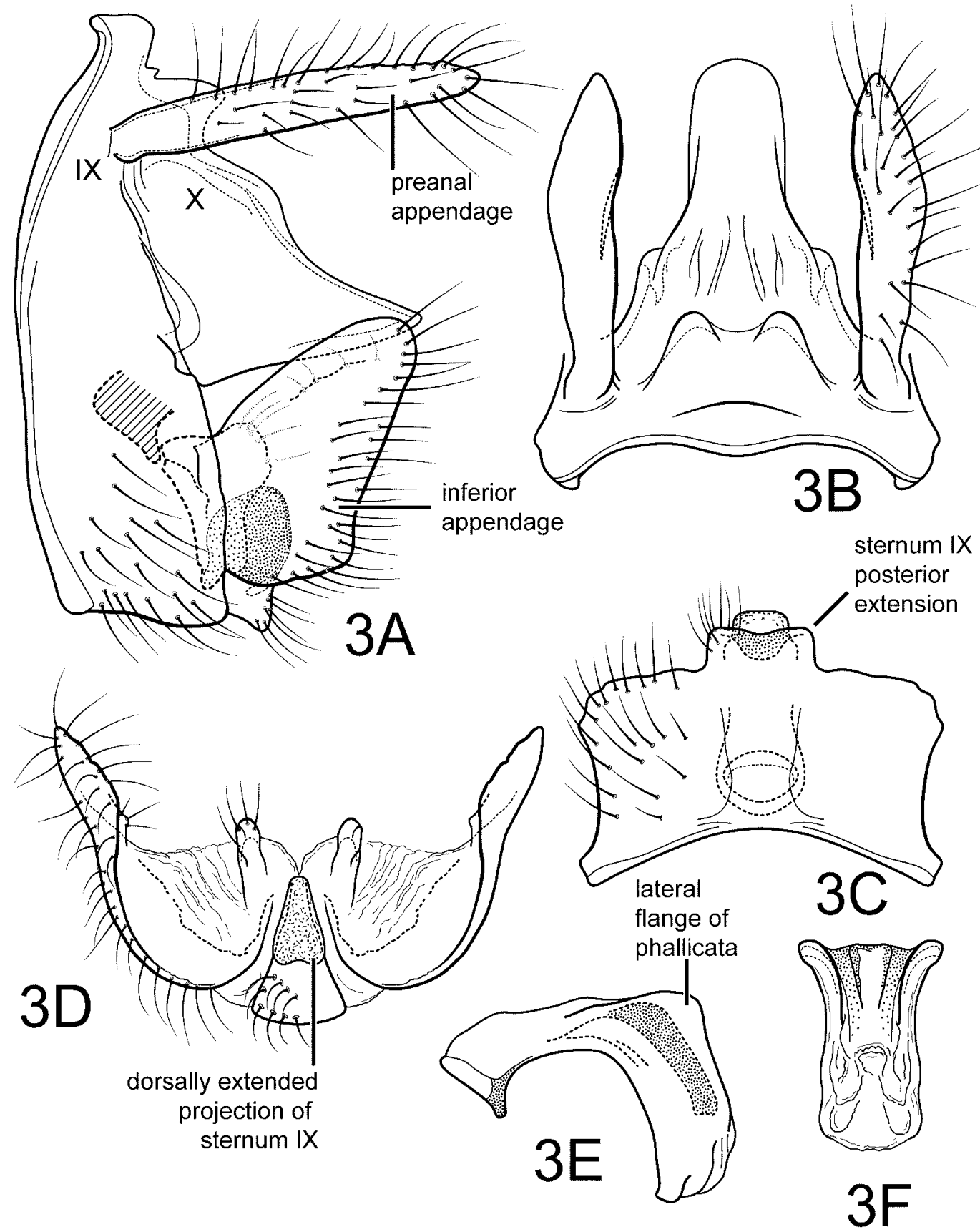

FIGURE 3. Tagalopsyche aethiopica Kimmins. Male genitalia: A—abdominal segments IX \& X, lateral (only base of phallic apparatus indicated in this and subsequent illustrations); B- same, dorsal; $\mathrm{C}$ - abdominal segment IX, ventral; D—inferior appendages and process of sternum IX, caudal; E—phallic apparatus, lateral; F—same, caudal. 


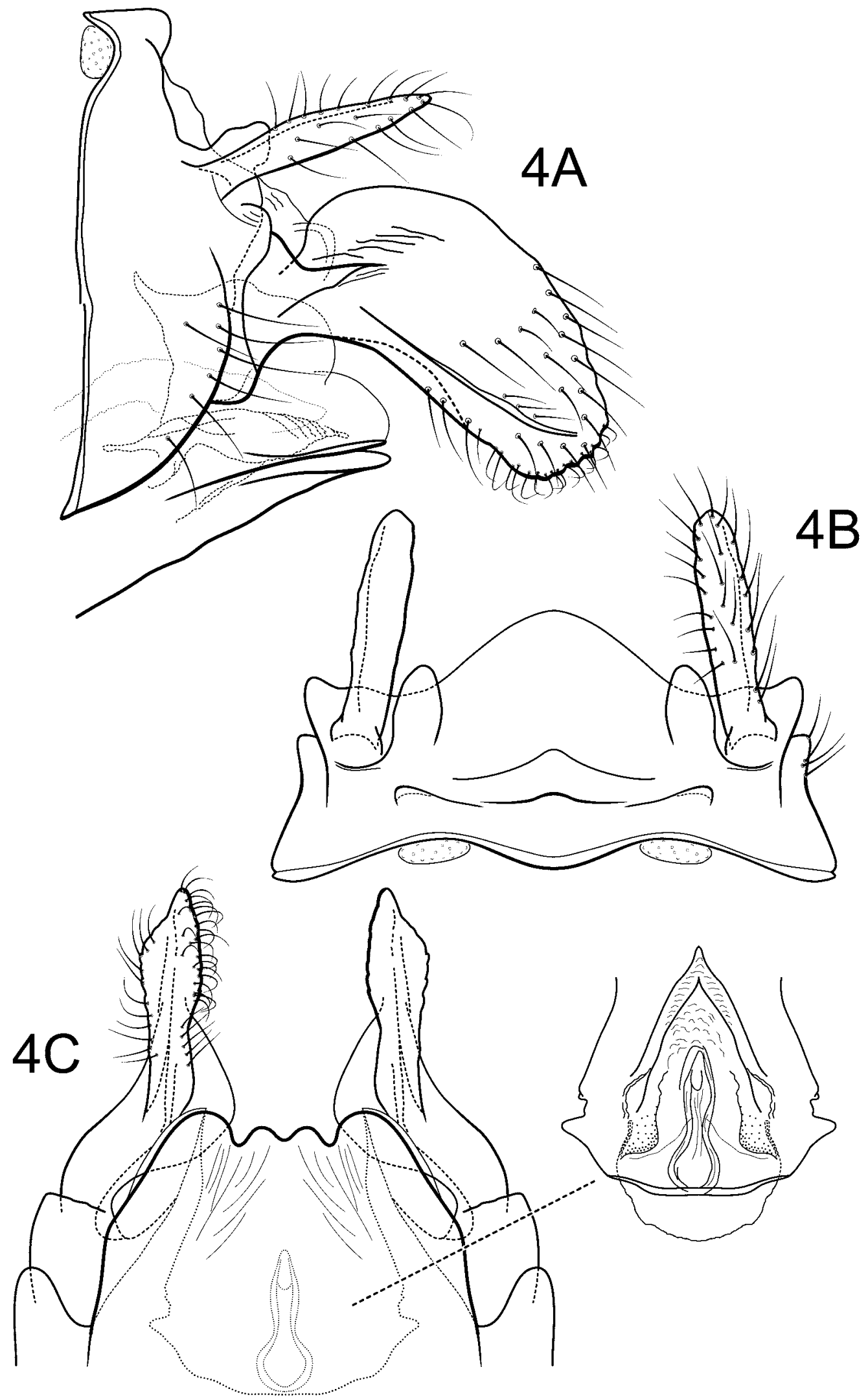

FIGURE 4. Tagalopsyche aethiopica Kimmins. Female genitalia: A—abdominal segments IX \& X, lateral; B-same, dorsal; C—same, ventral (inset: spermathecal sclerite complex).

Male. Abdominal segment IX annular, setose, especially ventrally; in lateral view anterior and posterior margins nearly parallel, shortest at insertion of preanal appendage; tergum IX short, not produced posteriorly; 
posterior extension of sternum IX short, less than $1 / 3$ length of sternum, in ventral view base narrow, apex entire, overall shape quadrate, apical margin with very shallow emargination, apicolateral corners smooth, setose, in lateral view subquadrate; posterior process of segment IX extended dorsally to form heavily sclerotized projection, surface entirely rugose, in caudal view projection narrowly triangular, in lateral view oval, in ventral view subtruncate, entire. Preanal appendage oblong, heavily setose, about as long as segment X, apex subacute. Inferior appendage spatulate, setose, apex slightly directed laterad, in lateral view auriculate, broad basally, gradually tapering to rounded apex, mesolateral surface with low setose ridge, basoventrally without processes, mesobasally with broad, flat process bearing apical setae. Tergum X saddle-shaped, broad, about $1 / 2$ width of segment IX, in lateral view triangular, apex acute, dorsolaterally with pair of short, digitate protuberances, in dorsal view apex rounded. Phallic apparatus short, compact; phallobase tubular, apparently fused with phallicata, basoventrally with short sclerotized flange that apparently articulates with base of fused inferior appendages; phallicata strongly down turned apically at nearly 90 degrees to phallobase, apex of phallicata with straight lateral sclerotized flanges and mesal membranous region, dorsolateral corners rounded, projecting; parameres absent; phallotremal sclerite not discernable.

Female. Segment IX short, in lateral view posterior margin straight, anteroventral margin rounded, setose. Tergum X short, less than half length of preanal appendages, in lateral view roughly triangular, apex rounded, in dorsal view broadly rounded apically; basolaterally with pair of long papillate processes. Preanal appendage long, digitate, setose. Lamella very large, constricted basally, in lateral view directed ventrad, dorsal margin broadly rounded, ventral margin straight, apex subtruncate, outer and inner surfaces setose, setae along apicoventral edge strongly recurved mesad; in ventral view lamella sinuate from base, apex straight, mesal surface concave. Gonopod plate basolateral edges produced in flanges, apex divided into 4 short rounded lobes, middle lobes shorter, surface with fine striations. Spermathecal sclerite complex, in ventral view triangular, apex acute, finely rugose and striate, laterally with wide, semimembranous flanges, medially with keyhole-shaped sclerite.

Material examined: ETHIOPIA: Lake Awasa, 6.xi.1960, at light - 1 male paratype (CNC); Bahar Dar, 8.xii.1964, M.E. Smith - 1 male (NMNH), same, 6.xii.1964 - 1 female (NMNH), same, 4.vii.1964, A.B. Gurney - 1 male, 3 females (NMNH); Black River near Awasa, 15.iv.1961, A. Tjønneland - 3 male paratypes, 2 female paratypes (NHM).

Distribution. Ethiopia.

\section{Tagalopsyche brunnea (Ulmer)}

Figs. 5-6

Setodes brunnea Ulmer, 1905: 90, figs. 3-5 [Type: Borobudur, Java, leg. 17.iii.1904, ded. 8.vi.1904, (K. Kraepelin), male, ZSZMH, destroyed. Neotype: Semarang, iii.1910, male, ZSZMH]. -Ulmer 1906: 105; 1907a: 17; 1907b: 146; 1913: 79.

Tagalopsyche brunnea (Ulmer) 1930: 468. —Weidner 1964: 96 [neotype designation]. -Ulmer 1951: 10, 22, 23, 24, 26, 417; 1957: 451.

Among the Oriental species, T. brunnea is distinguished by the slightly extended posterior region of sternum IX and its shallow mesal excavation. The inferior appendage is subrectangular in lateral view, perhaps most similar to that of T. udagama, new species, but in the later species the posterior extension of sternum IX is more prominent.

Adult. Length of forewing: male $6.5 \mathrm{~mm}(\mathrm{n}=1)$, female $6.5 \mathrm{~mm}(\mathrm{n}=1)$. Color brown.

Male. Abdominal segment IX annular, setose, especially ventrally; in lateral view anterior and posterior margins parallel, shortest at insertion of preanal appendage; tergum IX short, not produced posteriorly; posterior extension of sternum IX short, less than 1/3 length of sternum, in ventral view base narrow, apex excised, 


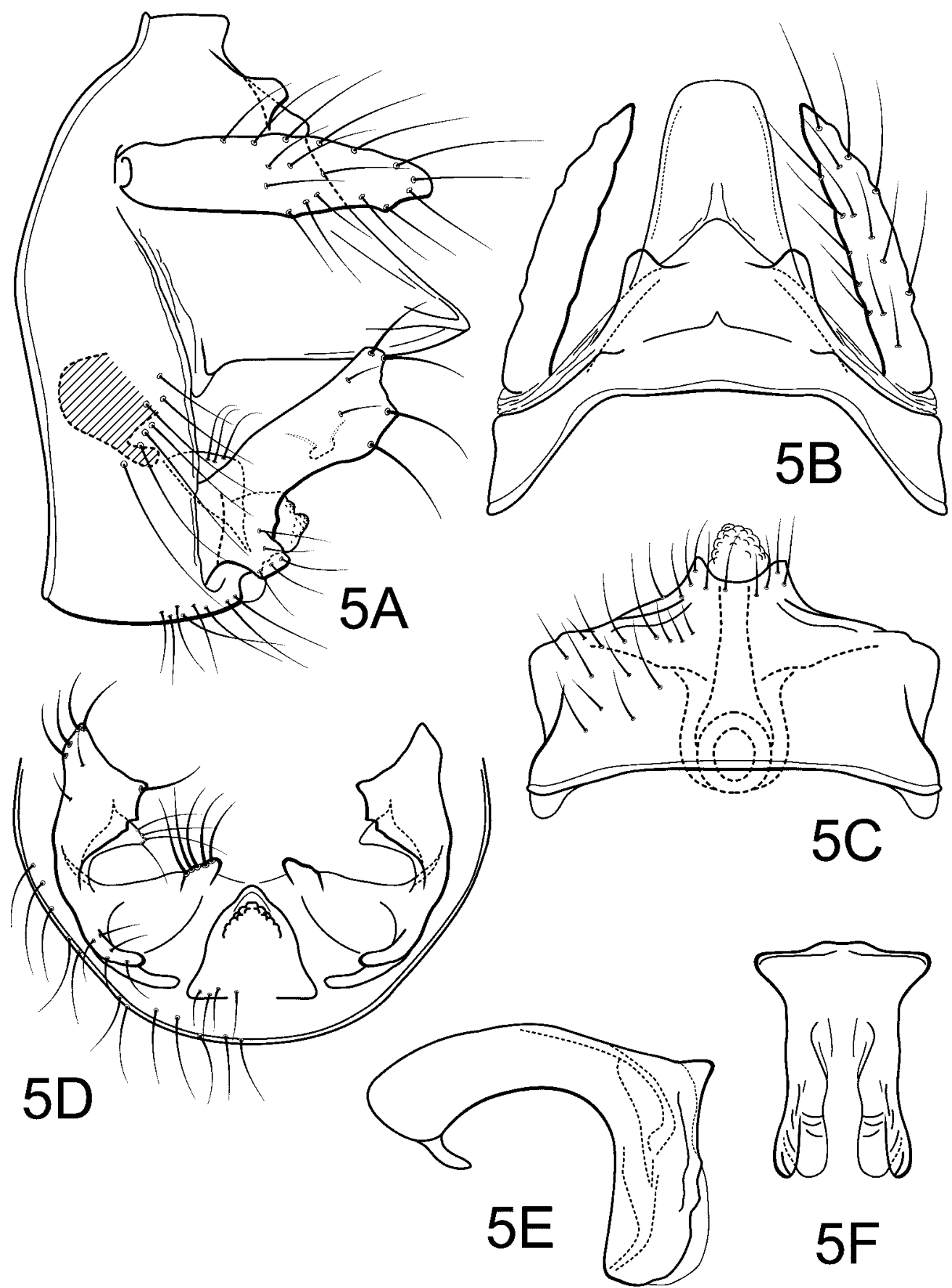

FIGURE 5. Tagalopsyche brunnea (Ulmer). Male genitalia: A—abdominal segments IX \& X, lateral; B-same, dorsal; $\mathrm{C}$-abdominal segment IX, ventral; D—inferior appendages and process of sternum IX, caudal; E—phallic apparatus, lateral; F-same, caudal.

overall shape subtriangular, apical margin with shallow, U-shaped excision, apicolateral corners smooth, setose, in lateral view rounded; posterior process of segment IX extended dorsad to form heavily sclerotized projection, surface rugose apicodorsally, in caudal view projection triangular, in lateral view rounded, in ventral view rounded, entire. Preanal appendage oblong, heavily setose, slightly shorter than segment X. Inferior appendage spatulate, setose, apex strongly curved mesad, in lateral view subrectangular, dorsal edge straight, ventral edge shallowly excavated, apicoventral edge slightly irregular, mesolateral surface with small triangular setose process, basoventrally with short, quadrate process bearing apical setae, mesobasally with small, broad, flat process bearing apical setae. Tergum X saddle-shaped, broad, about 1/2 width of segment IX, in lateral view triangular, apex acute, dorsolaterally with pair of short, digitate protuberances, in dorsal view 
apex rounded. Phallic apparatus short, compact; phallobase tubular, apparently fused with phallicata, basoventrally with short sclerotized flange apparently articulating with base of fused inferior appendages; phallicata strongly down turned apically at nearly 90 degrees to phallobase, apex of phallicata with straight lateral sclerotized flanges and mesal membranous region, dorsolateral corners square, slightly projecting; parameres absent; phallotremal sclerite not discernable.

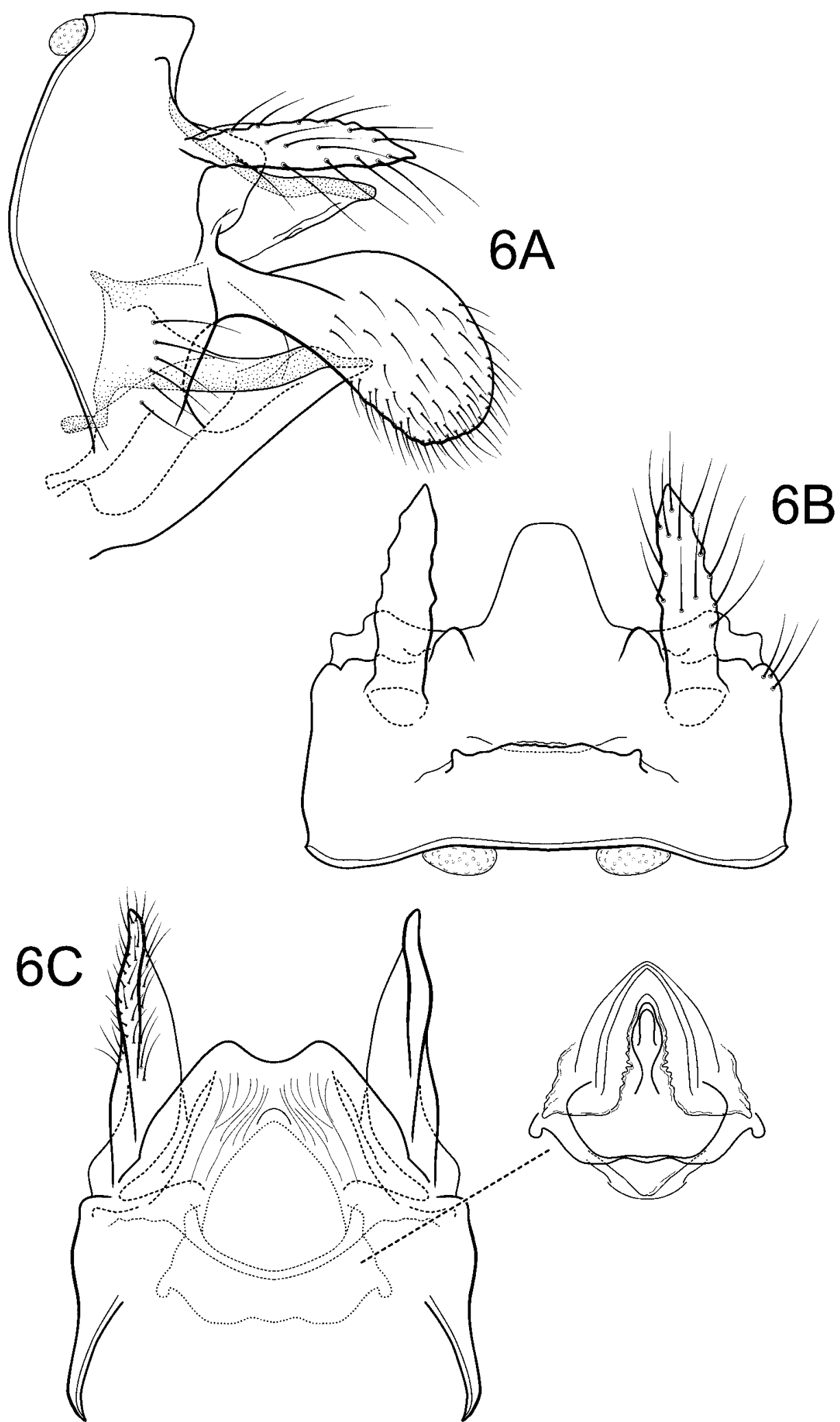

FIGURE 6. Tagalopsyche brunnea (Ulmer). Female genitalia: A—abdominal segments IX \& X, lateral; B-same, dorsal; C—same, ventral (inset: spermathecal sclerite complex). 
Female. Segment IX short, in lateral view posterior margin rounded, anteroventral margin indistinct, semimembranous, setose. Tergum X long, almost as long as preanal appendages, in lateral view triangular, apex subacute, in dorsal view subrectangular apically; basolaterally with pair of short papillate processes. Preanal appendage long, digitate, setose. Lamella very large, constricted basally, in lateral view directed ventrad, dorsal margin broadly rounded, ventral margin straight, apex rounded, outer and inner surfaces setose; in ventral view lamella straight, mesal surface concave. Gonopod plate basolateral edges produced in flanges, apex with broad excavation, surface with fine striations. Spermathecal sclerite complex, in ventral view oval, apex subacute, laterally with semimembranous flanges, medially with keyhole-shaped sclerite.

Material examined: INDONESIA: Java: Buitenzorg [Bogor], 3.iii.1930, Lieftinck — female (ZSZMH); Buitenzorg, iv.1908, E. Jacobson — female (ZSZMH); Wonosobo, iv.1909, E. Jacobson — female (ZSZMH); Samarang, 1910, MRt, E. Jacobson — male neotype (ZSZMH).

Distribution. Indonesia (Java).

\section{Tagalopsyche fletcheri Kimmins}

Figs. 7-8

Tagalopsyche fletcheri Kimmins, 1963b: 280, figs. 55-60 [Type: India, Palnis, 7000 ft., Kodaikanal, viii.1921 (T.B. Fletcher), male, NHM].

This Indian species is recognized by the strongly projecting dorsolateral corners of the phallic apparatus, the large, heavily rugose dorsal process of sternum IX, and the shape of the inferior appendage and its many seta bearing lobes and ridges. However, in the later character there is some variation in the number of lobes and their size. Also, the degree to which the inferior appendage is curved mesad is variable among individuals and affects the shape of the appendage when viewed laterally. Because of this variation, Tagalopsyche fletcheri might be confused with the other Indian species, T. apratita, new species, and T. udagama, new species, based solely on the inferior appendages. However, T. apratita has a distinct basoventral lobe on the inferior appendage and the dorsal sclerotized region of sternum IX is differently shaped (Fig. 10A) while T. udagama has little development of the basoventral region of the inferior appendage and the dorsal region of sternum IX has a different shape (Fig. 16A). Of the 3 species, T. fletcheri is the largest in size.

Adult. Length of forewing: male 7.5-8.5 mm $(n=5)$, female 8.1-9.0 mm $(n=4)$. Color brown, covered with scattered cream hairs, with larger patch of cream hairs at arculus; female coloration as in male.

Male. Abdominal segment IX annular, setose, especially ventrally; in lateral view anterior and posterior margins parallel, shortest at insertion of preanal appendage; tergum IX short, produced posteriorly as small shelf; posterior extension of sternum IX short, 1/2 length of sternum, in ventral view base narrow, apex entire, overall shape deltoid, apical margin with shallow infolding, apicolateral corners slightly rugose, setose, in lateral view rounded; posterior process of segment IX extended dorsally to form heavily sclerotized projection, surface entirely rugose, in caudal view projection triangular, lateral margins slightly concave, in lateral view oval, in ventral view subtriangular, entire. Preanal appendage oblong, heavily setose, about as long as segment $\mathrm{X}$, apex acute. Inferior appendage spatulate, setose, apex strongly curved mesad, in lateral view ovate, dorsal and ventral edges slightly convex, apex with $\mathrm{V}$-shaped notch, mesolateral surface with small irregular setose processes, basoventrally with row of short processes bearing apical setae, mesobasally with broad, flat, crenulated process bearing apical setae. Tergum X saddle-shaped, broad, about 1/2 width of segment IX, in lateral view triangular, apex acute, dorsolaterally with pair of short, digitate protuberances, in dorsal view apex rounded. Phallic apparatus short, compact; phallobase tubular, apparently fused with phallicata, basoventrally with short sclerotized flange that apparently articulates with base of fused inferior appendages; phallicata strongly down turned apically at nearly 90 degrees to phallobase, apex of phallicata with rounded lateral scle- 
rotized flanges and mesal membranous region, dorsolateral corners digitate, strongly projecting; parameres absent; phallotremal sclerite not discernable.

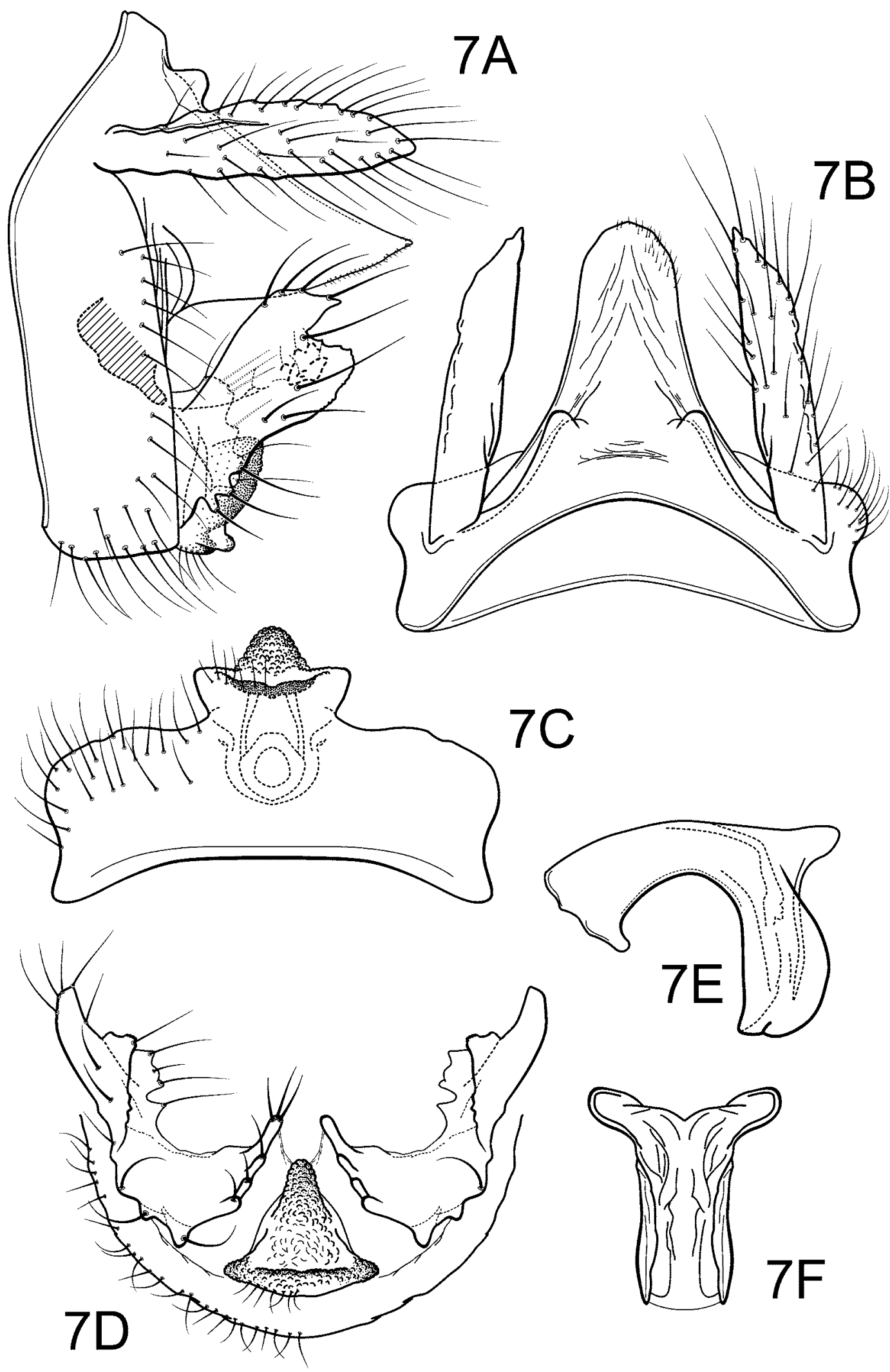

FIGURE 7. Tagalopsyche fletcheri Kimmins. Male genitalia: A—abdominal segments IX \& X, lateral; B- same, dorsal; C—abdominal segment IX, ventral; D—inferior appendages and process of sternum IX, caudal; E—phallic apparatus, lateral; F-same, caudal. 


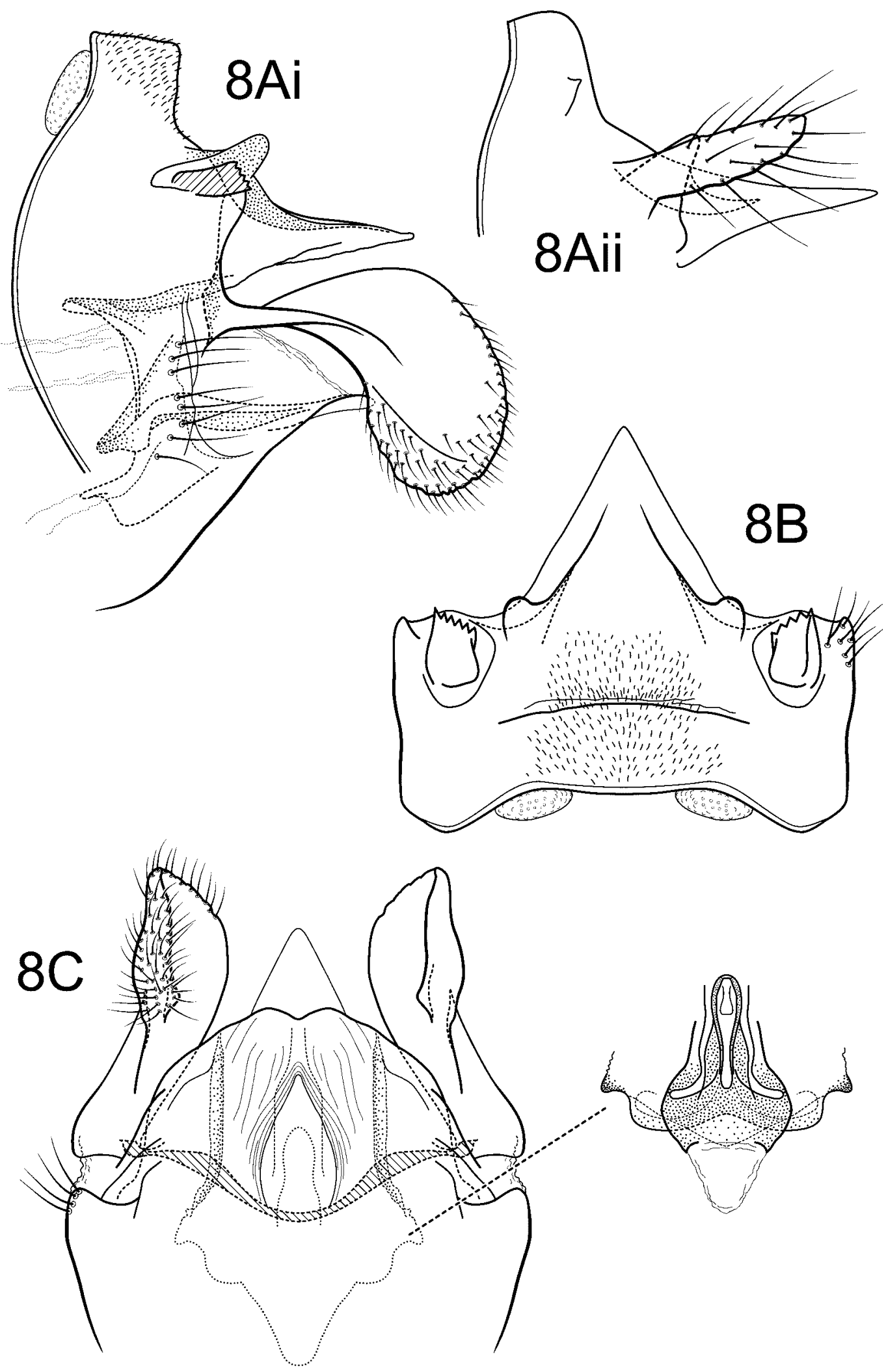

FIGURE 8. Tagalopsyche fletcheri Kimmins. Female genitalia: $\mathrm{Ai}-$ abdominal segments IX \& X, lateral (female paratype); Aii-preanal appendage (specimen from Madras, India); B— abdominal segments IX \& X (female paratype), dorsal; C—same, ventral (inset: spermathecal sclerite complex).

Female. Segment IX short, in lateral view posterior margin rounded, anteroventral margin indistinct, semimembranous, setose. Tergum $X$ long, about $1 / 3$ longer than preanal appendages, in lateral view narrowly 
triangular, apex acute, in dorsal view acutely triangular apically; basolaterally with pair of short papillate processes. Preanal appendage short, digitate, setose (broken on both sides of female paratype illustrated). Lamella very large, very narrowly constricted basally, in lateral view strongly directed ventrad, dorsal and ventral margins broadly rounded, apex rounded, outer and inner surfaces setose; in ventral view lamella slightly curved outward from base, mesal surface concave. Gonopod plate basolateral edges produced in flanges, apex with small excavation, surface with fine striation. Spermathecal sclerite complex, in ventral view rectangular, apex broad, laterally with semimembranous flanges, medially with keyhole-shaped sclerite.

Material examined: INDIA: Kodaikanal [S. India], 7000 ft., Brit. Mus. 1936-512, 24.iii.1936 — male paratype (CNC), same, 23.iii.1936 - male paratype (NHM), 26.iii.1939 - female paratype (NHM); Madras: Avalanche, 28-30.xii.1958, F. Schmid - 35 males, 12 females (CNC); Meppadi, 9.i.1959, F. Schmid - 1 male (CNC); Kodaikanal, 6.xii.1961, F. Schmid - 1 male (CNC); Ottakada, 5.i.1962, F. Schmid - 1 male (CNC); Katagari, 16.i.1959, F. Schmid - 1 female (CNC).

Distribution. India.

\section{Tagalopsyche sisyroides Banks}

Fig. 9

Tagalopsyche sisyroides Banks, 1913: 177, figs. 2, 7 [Type: Los Baños, Philippine Islands (P.I. Baker), male, MCZ]. — Banks 1916: 213; -Ulmer 1930: 404, 492, 498; 1951: 15, 417, 420-421; 1955: 515-517; 1957: 438, 451.

Tagalopsyche sisyroides is easily recognized by the elongate, deeply excised posterior extension of sternum IX and by the spatulate ventral lobe on the inferior appendage. In the former character only, it is similar to $T$. kjaerandseni, new species, but the 2 species are distinct in all other aspects. The wings of $T$. sisyroides as indicated in the literature (Banks 1913; Ulmer 1930) are broad and truncate, similar to those of $T$. jolandae, new species.

Adult. Length of forewing: unknown, wing broken/missing. Color dark brown.

Male. Abdominal segment IX annular, setose, especially ventrally; in lateral view anterior margin nearly straight, posterior margin extended ventrolaterally, shortest at insertion of preanal appendage; tergum IX short, not produced posteriorly; posterior extension of sternum IX long, approximately equal in length to sternum, in ventral view base wide, apex deeply excised, forming paired processes, paired processes subulate, apices rounded, apical margin with deep V-shaped excision, in lateral view digitate, slightly tapering to rounded apex; posterior process of segment IX extended dorsad to form heavily sclerotized projection, surface smooth, in caudal view projection narrowly triangular, lateral margins concave, in lateral view elongate, in ventral view subtriangular, entire. Preanal appendage lanceolate, heavily setose, slightly shorter than segment $\mathrm{X}$, apex subacute. Inferior appendage crescentric, setose, in lateral view apically rounded, with digitate dorsal lobe and heavily sclerotized, slightly upturned, spatulate ventral lobe, mesolateral surface with small setose process, basoventrally without processes, mesobasally with subtriangular process bearing apical setae. Tergum X saddle-shaped, broad, about 1/2 width of segment IX, in lateral view triangular, apex acute, dorsolaterally with pair of short, digitate protuberances, in dorsal view apex subacute. Phallic apparatus short, compact; phallobase tubular, apparently fused with phallicata, basoventrally with long sclerotized flange that apparently articulates with base of fused inferior appendages; phallicata strongly down turned apically at nearly 90 degrees to phallobase, apex of phallicata with apicoventrally rounded lateral sclerotized flange and mesal membranous region, dorsolateral corners rounded, projecting; parameres absent; phallotremal sclerite not discernable.

Female. Unknown.

Material examined: PHILIPPINES: Los Baños, P.I. Baker — male holotype (MCZ).

Distribution. Indonesia (Sumatra), Philippines. 

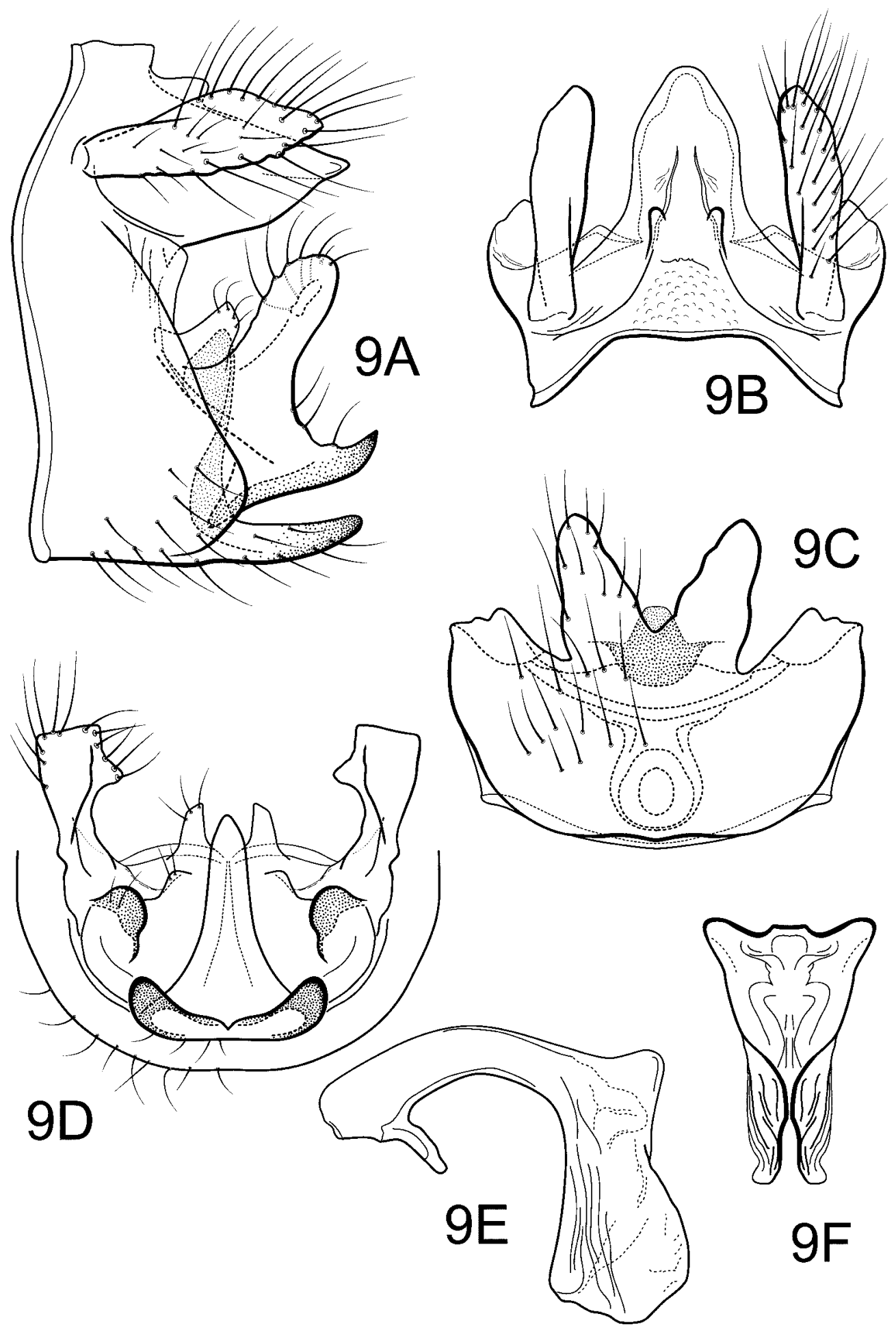

FIGURE 9. Tagalopsyche sisyroides Banks. Male genitalia: A—abdominal segments IX \& X, lateral; B- same, dorsal; $\mathrm{C}$-abdominal segment IX, ventral; D—inferior appendages and process of sternum IX, caudal; E—phallic apparatus, lateral; F-same, caudal.

\section{Tagalopsyche apratita, new species}

Figs. 10-11

This Indian species is similar to T. fletcheri and T. udagama, new species, but differs from those in the presence of a distinct basoventral process on the inferior appendage. The 3 species differ in the structure of the sclerotized dorsal region of sternum IX as illustrated. 


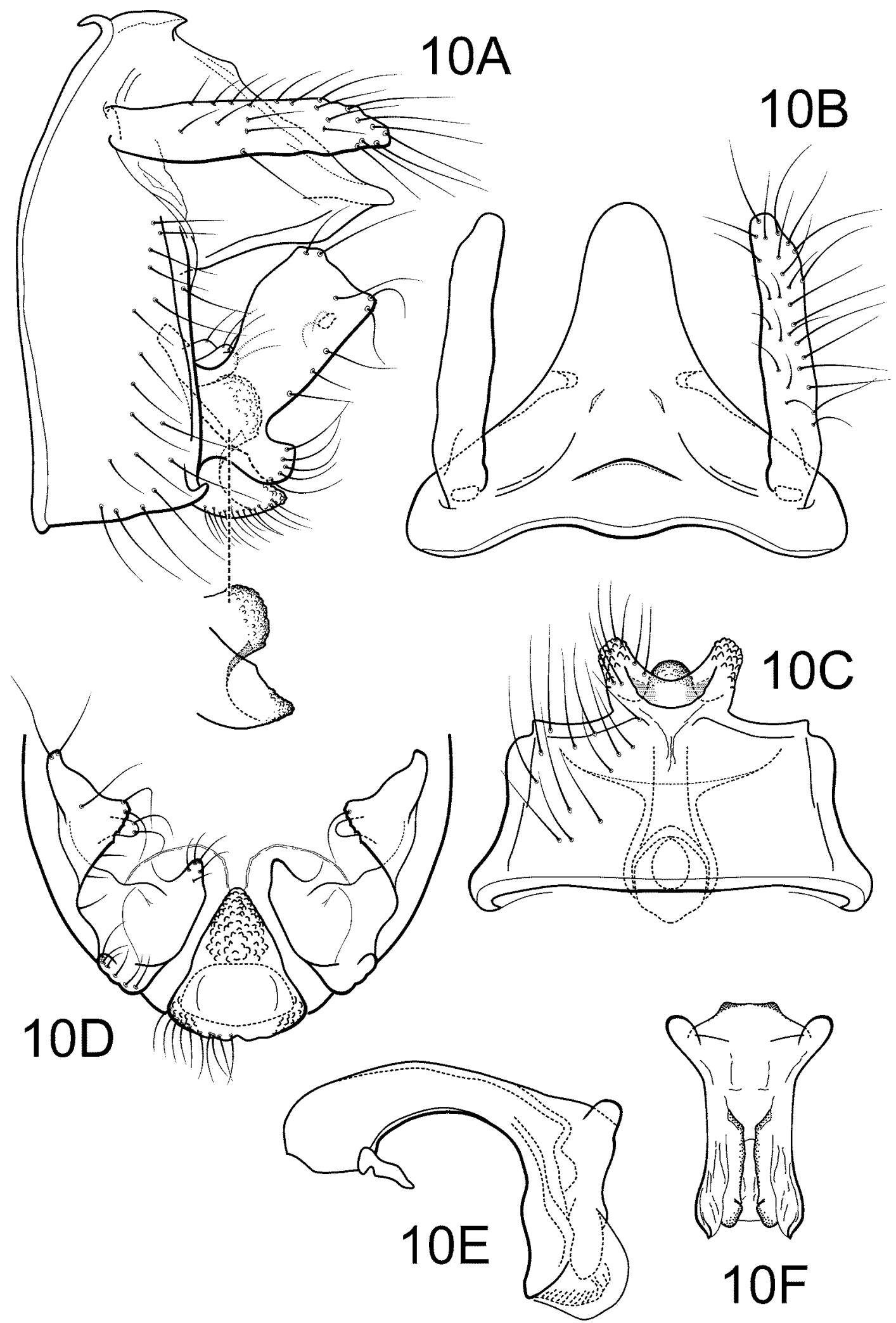

FIGURE 10. Tagalopsyche apratita, new species. Male genitalia: A-abdominal segments IX \& X, lateral (inset: process of sternum IX); B- same, dorsal; C-abdominal segment IX, ventral; D—inferior appendages and process of sternum IX, caudal; E—phallic apparatus, lateral; F—same, caudal. 

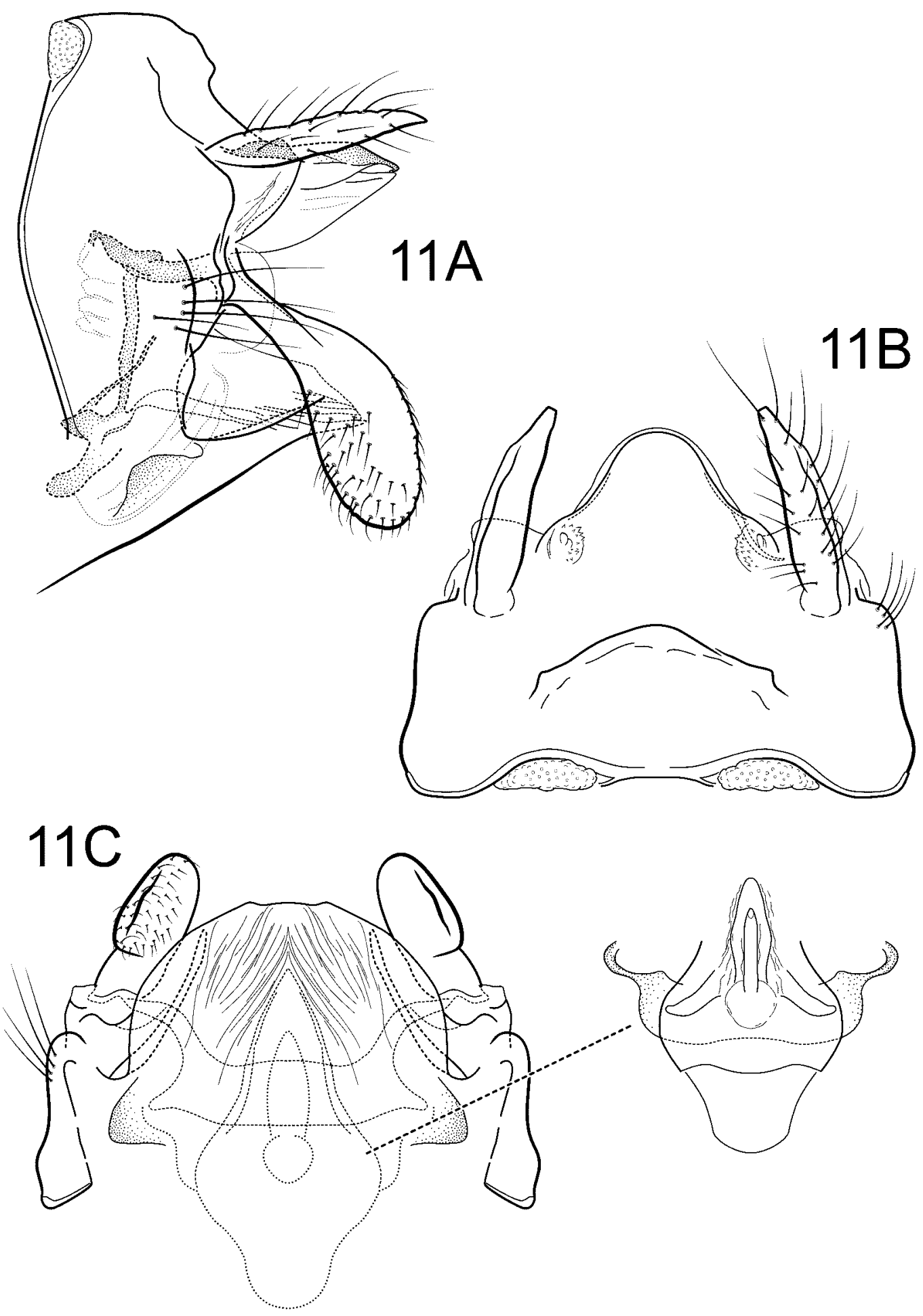

FIGURE 11. Tagalopsyche apratita, new species. Female genitalia: A—abdominal segments IX \& X, lateral; B—same, dorsal; C-same, ventral (inset: spermathecal sclerite complex).

Adult. Length of forewing: male $6.5-7.0 \mathrm{~mm}(\mathrm{n}=3)$, female $7.0 \mathrm{~mm}(\mathrm{n}=2)$. Color brown, male with scattered patches of cream and white hairs and distinct white spots at arculus, stigma, and apical wing margin, larger white spot near base of radius; female coloration as in male, but all patches and spots cream colored.

Male. Abdominal segment IX annular, setose, especially ventrally; in lateral view anterior and posterior margins parallel, shortest at insertion of preanal appendage; tergum IX short, slightly produced posteriorly as small shelf; posterior extension of sternum IX short, 1/2 length of sternum, in ventral view base narrow, apex 
excised, overall shape subtriangular, apical margin with U-shaped excision, apicolateral corners rugose, setose, in lateral view subtriangular; posterior process of segment IX extended dorsad to form heavily sclerotized projection, surface entirely rugose, in caudal view projection triangular, in lateral view rounded, in ventral view rounded, entire. Preanal appendage oblong, heavily setose, about as long as segment X, apex subacute. Inferior appendage spatulate, setose, apex strongly curved mesad, in lateral view subrectangular, dorsal and ventral edges nearly parallel, apicoventral edge square, mesolateral surface with small digitate setose process, basoventrally with rounded process bearing apical setae, mesobasally with subtriangular process bearing apical setae. Tergum X saddle-shaped, broad, about $1 / 2$ width of segment IX, in lateral view triangular, apex acute, dorsolaterally with pair of small, low protuberances, in dorsal view apex rounded. Phallic apparatus short, compact; phallobase tubular, apparently fused with phallicata, basoventrally with long sclerotized flange that apparently articulates with base of fused inferior appendages; phallicata strongly down turned apically at nearly 90 degrees to phallobase, apex of phallicata with apicoventrally rounded lateral sclerotized flange and mesal membranous region, dorsolateral corners digitate, projecting; parameres absent; phallotremal sclerite not discernable.

Female. Segment IX short, in lateral view posterior margin slightly rounded, anteroventral margin sinuous. Tergum X short, slightly less than length of preanal appendages, in lateral view triangular, apex subacute, ventrally with broad secondary plate-like sclerite, in dorsal view broadly rounded apically (secondary sclerite also broadly rounded); basolaterally with pair of short, spiculate, papillate processes. Preanal appendage long, digitate, setose. Lamella very large, very narrowly constricted basally, in lateral view strongly directed ventrad, dorsal and ventral margins rounded, apex rounded, outer and inner surfaces setose; in ventral view lamella straight, mesal surface concave. Gonopod plate basolateral edges produced in flanges, apex with very slight excavation, surface with fine striation. Spermathecal sclerite complex, in ventral view oval, apex subacute, laterally with semimembranous flanges, medially with keyhole-shaped sclerite.

Holotype male: INDIA: (U.J.K.H.) [Assam, United Khasi-Jaintia Hills District], Nongjni, 19.iv.1960, F. Schmid (CNC).

Paratypes: same data as holotype -2 males, 2 females (CNC); INDIA: Meghalaya: Nongph-Forest, 25-28.iv.1980, A. Freidberg — 1 male, 1 female (NMNH).

Distribution. India.

Etymology. Fernand Schmid developed the custom of using Sanskrit names when describing the species he collected in India. He applied the name apratita to this new species of Tagalopsyche. According to the Cologne Digital Sanskrit Lexicon (http://webapps.uni-koeln.de/tamil/) the word means unapproached, unattackable or not understood, uncommon (as an expression) or not merry, sad. The epithet is to be regarded as a noun in apposition.

\section{Tagalopsyche jolandae, new species}

Figs. 12-14

This species, with broad wings, also has distinctly shaped inferior appendages which are overall deltoid in shape and narrowest in the middle. The shape of the dorsal sclerotization of sternum IX is also unique and distinctly elongate oval. The genitalia bear a slight resemblance to $T$. brunnea, but in $T$. jolandae the forewings are shorter and broader.

Adult. Length of forewing: male 5.7-6.5 mm ( $\mathrm{n}=3)$, female 5.5-6.3 mm ( $\mathrm{n}=2)$. Color brown (in alcohol).

Male. Abdominal segment IX annular, setose, especially ventrally; in lateral view anterior and posterior margins parallel, shortest at insertion of preanal appendage; tergum IX short, not produced posteriorly; posterior extension of sternum IX short, 1/2 length of sternum, in ventral view base narrow, apex entire, overall shape quadrate, apical margin with shallow, U-shaped excision, apicolateral corners rugose, setose, in lateral 
view rounded; posterior process of segment IX extended dorsad to form heavily sclerotized projection, surface entirely rugose, in caudal view projection ovate, in lateral view elongate oval, in ventral view subtriangular, entire. Preanal appendage lanceolate, heavily setose, slightly shorter than segment X, apex subacute. Inferior appendage spatulate, setose, apex curved mesad, in lateral view narrow subbasally, widening apically, apicoventral corner extended, subacute, mesolateral surface with small triangular setose process, basoventrally with short, irregular processes bearing apical setae, mesobasally with subtriangular process bearing apical setae. Tergum X saddle-shaped, broad, about 1/2 width of segment IX, in lateral view triangular, apex acute, dorsolaterally with pair of low, short, digitate protuberances, in dorsal view apex rounded. Phallic apparatus short, compact; phallobase tubular, apparently fused with phallicata, basoventrally with short sclerotized flange that apparently articulates with base of fused inferior appendages; phallicata strongly down turned apically at nearly 90 degrees to phallobase, dorsolateral corners digitate, projecting; parameres absent; phallotremal sclerite not discernable.

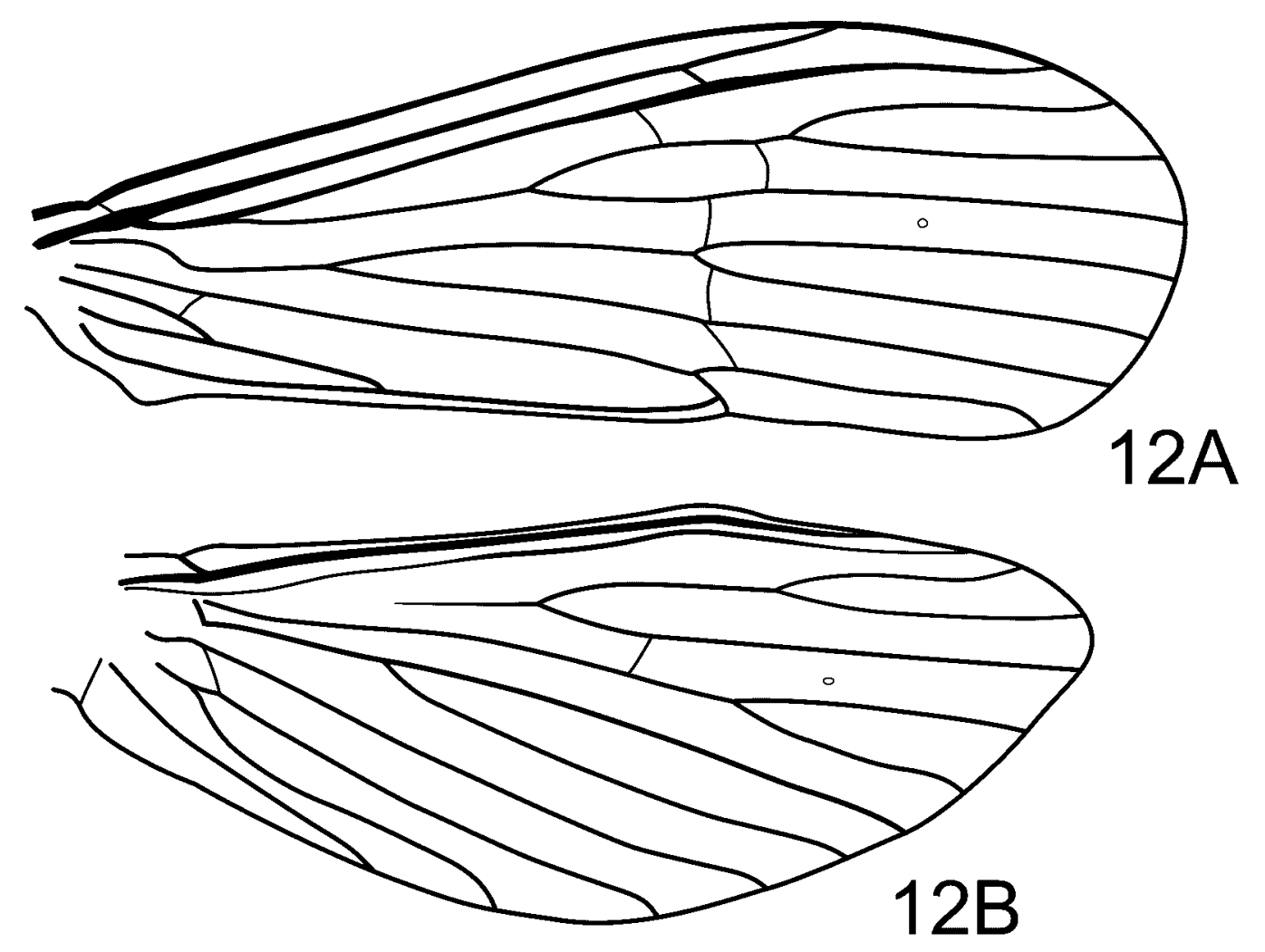

FIGURE 12. Tagalopsyche jolandae, new species. Wings: A—forewing; B-hind wing.

Female. Segment IX short, in lateral view posterior margin slightly rounded, anteroventral margin indistinct, semimembranous. Tergum $\mathrm{X}$ long, almost as long as preanal appendages (but both segment $\mathrm{X}$ and preanal appendages short compared to other species), in lateral view broadly triangular, apex acute, ventrally with secondary plate-like sclerite, in dorsal view broadly rounded apically (secondary sclerite also broadly rounded); basolaterally with pair of short papillate processes. Preanal appendage short, digitate, setose. Lamella very large, very narrowly constricted basally, in lateral view directed ventrad, dorsal margin broadly rounded, ventral margin straight, apex rounded, outer and inner surfaces setose; in ventral view lamella straight, mesal surface concave. Gonopod plate basolateral edges produced in flanges, apex with broad excavation, surface with fine striation. Spermathecal sclerite complex, in ventral view broadly oval, apex broad, laterally with broad, auriculate, semimembranous flanges, medially with weakly developed keyhole-shaped sclerite. 


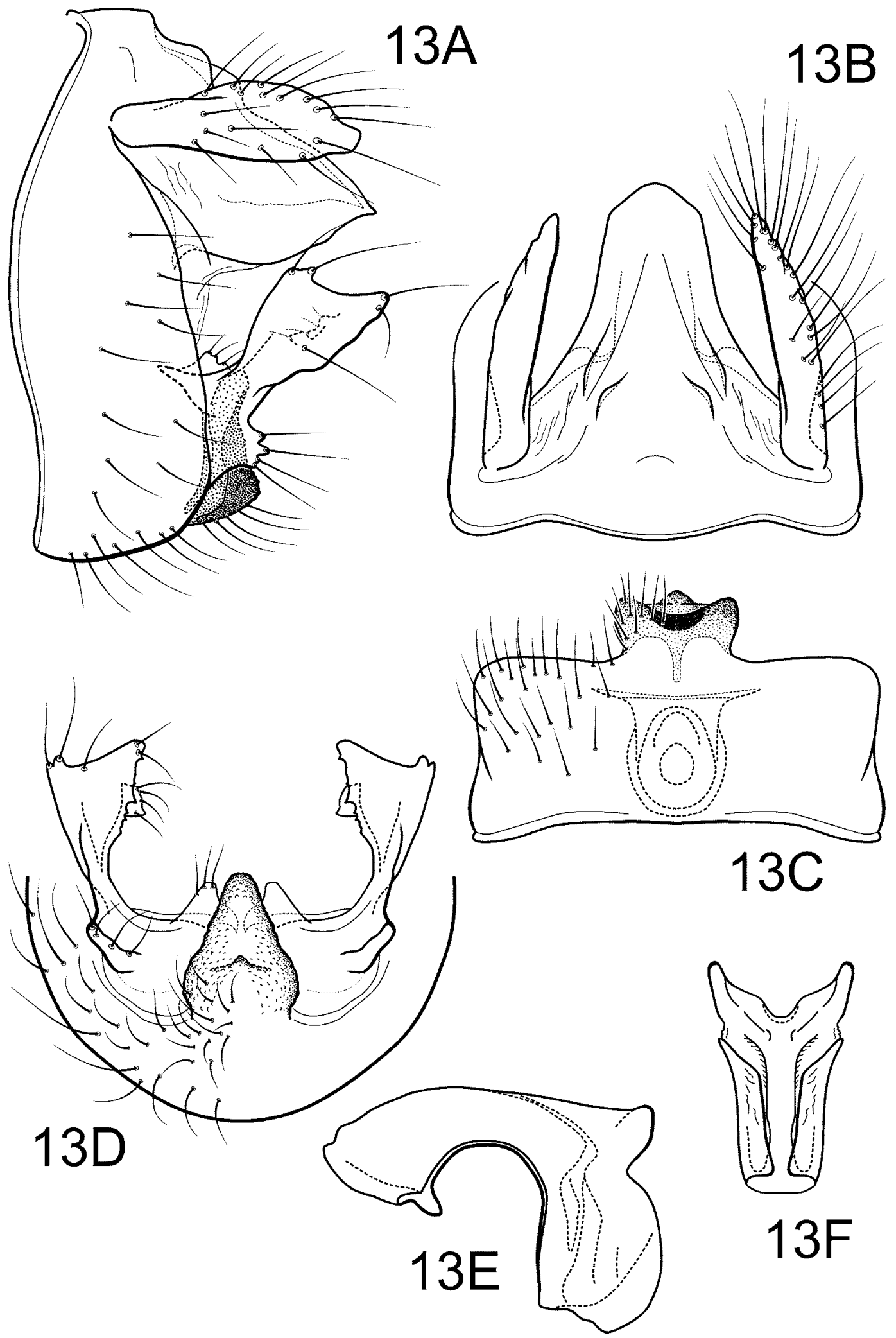

FIGURE 13. Tagalopsyche jolandae, new species. Male genitalia: A—abdominal segments IX \& X, lateral; B- same, dorsal; C-abdominal segment IX, ventral; D—inferior appendages and process of sternum IX, caudal; E-phallic apparatus, lateral; $\mathrm{F}$-same, caudal.

Holotype male: BRUNEI: Temburong: Temburong River just upstream jct. Sungai Wong, $114^{\circ} 40^{\prime} \mathrm{E}$, 4³6’ N, 140 m, 4.iv.1990, M. Coode (UMSP000108204) (UMSP). 


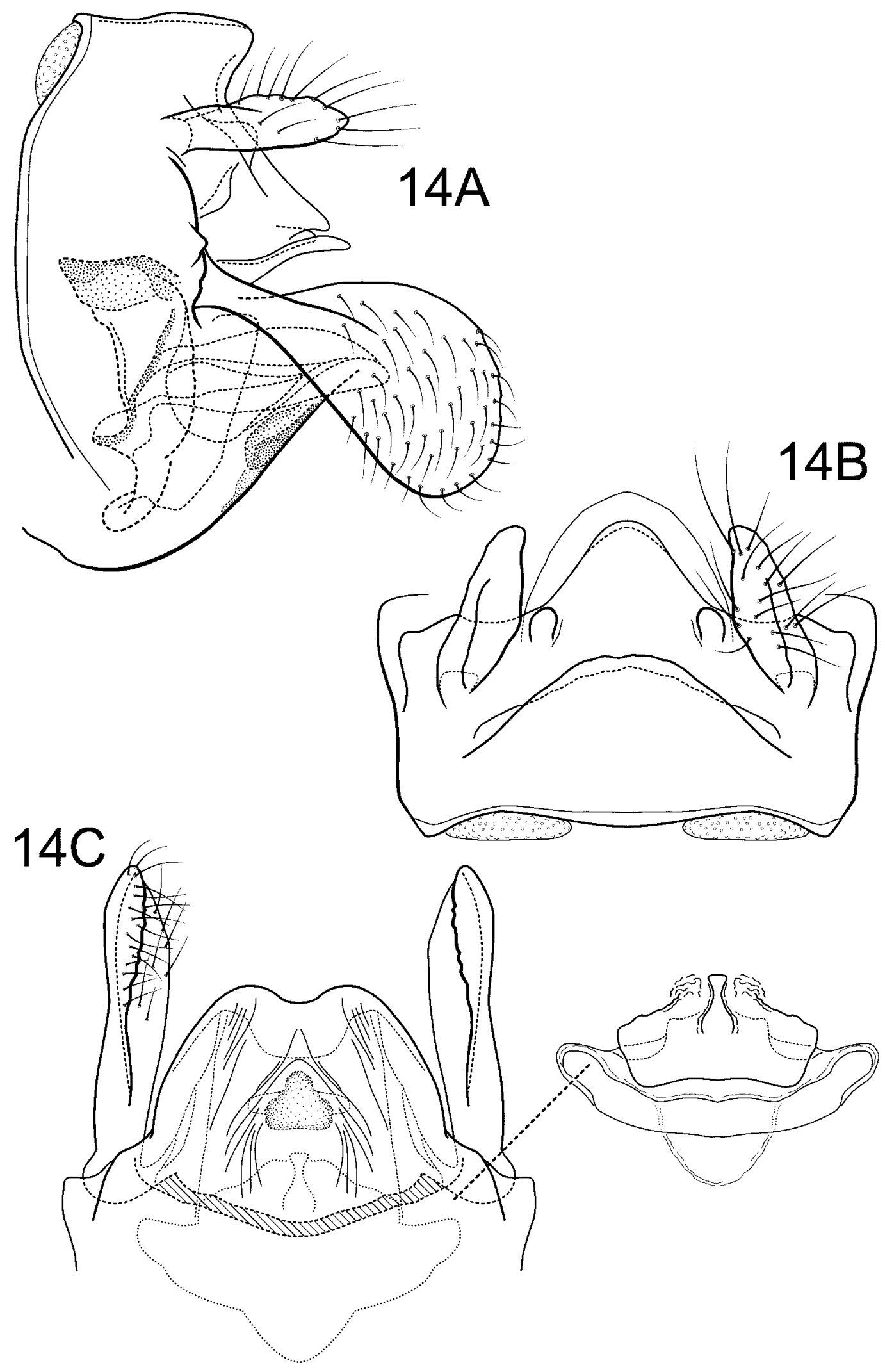

FIGURE 14. Tagalopsyche jolandae, new species. Female genitalia: A—abdominal segments IX \& X, lateral; B—same, dorsal; C—same, ventral (inset: spermathecal sclerite complex).

Paratypes: MALAYSIA: Sabah: $60 \mathrm{~km}$ west Lahad Datu, DVFC, Sg. Segama on bridge, $117^{\circ} 48^{\prime} \mathrm{E}$, $4^{\circ} 58^{\prime}$ N, 150 m, 14.iii.1987, J. Huisman — 1 male (RMNH); confl. Sg. Maga, Sg. Pa Sia, $115^{\circ} 40^{\prime}$ E, 426’ N, 
1210 m, 2.iv.1987, J. Huisman — 1 male (UMSP); 75 km west Lahad Datu, confl. Sg. Sabran, Sg. Danum, $117^{\circ} 41^{\prime} \mathrm{E}, 4^{\circ} 57^{\prime} \mathrm{N}, 200$ m, 23.x.1987, J. Huisman - 1 female (RMNH); Ulu Rurun, 11540’30'E, 4²2’N, 1400 m, 20.xii.1986, J. Huisman — 1 female (UMSP).

Distribution. Brunei, Malaysia (Sabah).

Etymology. We take great pleasure in naming this species in honor of Jolanda Huisman in recognition of her collecting efforts over several years on the island of Borneo which has resulted in the discovery of many new and interesting species of caddisflies.

\section{Tagalopsyche kjaerandseni, new species}

Fig. 1-2, 15

This, only the second African species, possesses a genitalic morphology unique within the genus. The new species is easily separated from all the other species in having the posterior extension of sternum IX deeply excised, forming paired processes; the dorsal sclerotized process of sternum IX large, heavily sclerotized, and excised mesally; and in having tergum $\mathrm{X}$ with a pair of lateral processes. In addition, the lateral flanges of the phallicata are especially heavily sclerotized in this species.

Adult. Length of forewing: male 6.6-6.9 mm ( $\mathrm{n}=3$ ). Color brown (in alcohol).

Male. Abdominal segment IX annular, setose, especially ventrally; in lateral view anterior and posterior margins nearly parallel, shortest at insertion of preanal appendage; tergum IX short, produced posteriorly as small shelf; posterior extension of sternum IX long, approximately equal in length to sternum, in ventral view base wide, apex deeply excised, forming paired processes, paired processes subulate, apices obliquely truncate, apical margin with deep U-shaped excision, in lateral view digitate, tapering to acute apex; posterior process of segment IX extended dorsad to form heavily sclerotized projection, surface smooth, in caudal view projection triangular, lateral margins deeply concave, in lateral view subtruncate, in ventral view rounded, excised mesally. Preanal appendage lanceolate, heavily setose, shorter than segment X, apex subacute. Inferior appendage spatulate, setose, apex strongly curved mesad, in lateral view subrectangular, dorsal edge slightly convex, ventral edge straight, mesolateral surface without processes, basoventrally with rounded process bearing apical setae, mesobasally with subtriangular process bearing apical setae. Tergum X saddleshaped, broad, about 1/2 width of segment IX, in lateral view triangular, apex with pair of triangular, subacute, lateral processes, dorsolaterally with pair of prominent, digitate protuberances, in dorsal view apex trifid. Phallic apparatus short, compact; phallobase tubular, apparently fused with phallicata, basoventrally without flange, but phallobase itself articulating with base of fused inferior appendages; phallicata strongly down turned apically at nearly 70 degrees to phallobase, apex of phallicata with straight, heavily sclerotized lateral flange and mesal membranous region, dorsolateral corners rounded, not projecting; parameres absent; phallotremal sclerite not discernable.

Female. Unknown.

Holotype male: GHANA: Volta Region: Agumatsu Waterfalls, Wli, Station 12, 16.xi.1993, NUFUproject (UMSP000108205) (UMSP).

Paratypes: GHANA: Volta Region: River Uwue south of Lipke Mate, 6.xi.1995, light-trap, NUFUproject - 1 male (UMSP); Eastern Region: Bothi Fall, 14.x.1994, light-trap, NUFU-project - 1 male (ZMBN).

Distribution. Ghana.

Etymology. We are pleased to name this new species in honor of our friend and colleague Dr. Jostein Kjærandsen who collected it and in recognition of his important work on the caddisflies of Ghana. 

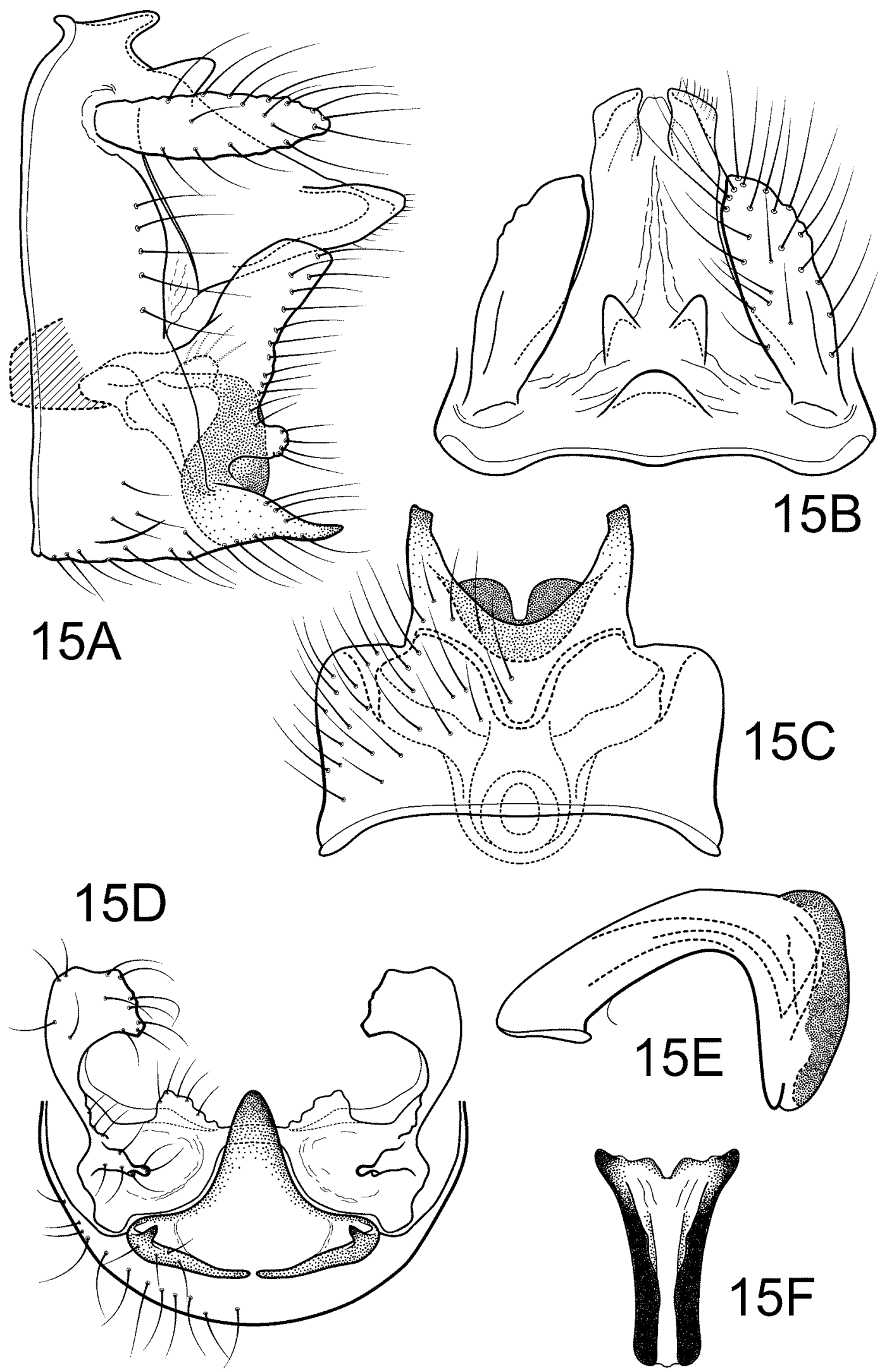

FIGURE 15. Tagalopsyche kjaerandseni, new species. Male genitalia: A—abdominal segments IX \& X, lateral; Bsame, dorsal; C—abdominal segment IX, ventral; D—inferior appendages and process of sternum IX, caudal; E—phallic apparatus, lateral; F-same, caudal. 


\section{Tagalopsyche udagama, new species}

Fig. 16

As discussed above, this species is similar to T. fletcheri and T. apratita, but differs in details of the inferior appendage and sternum IX.
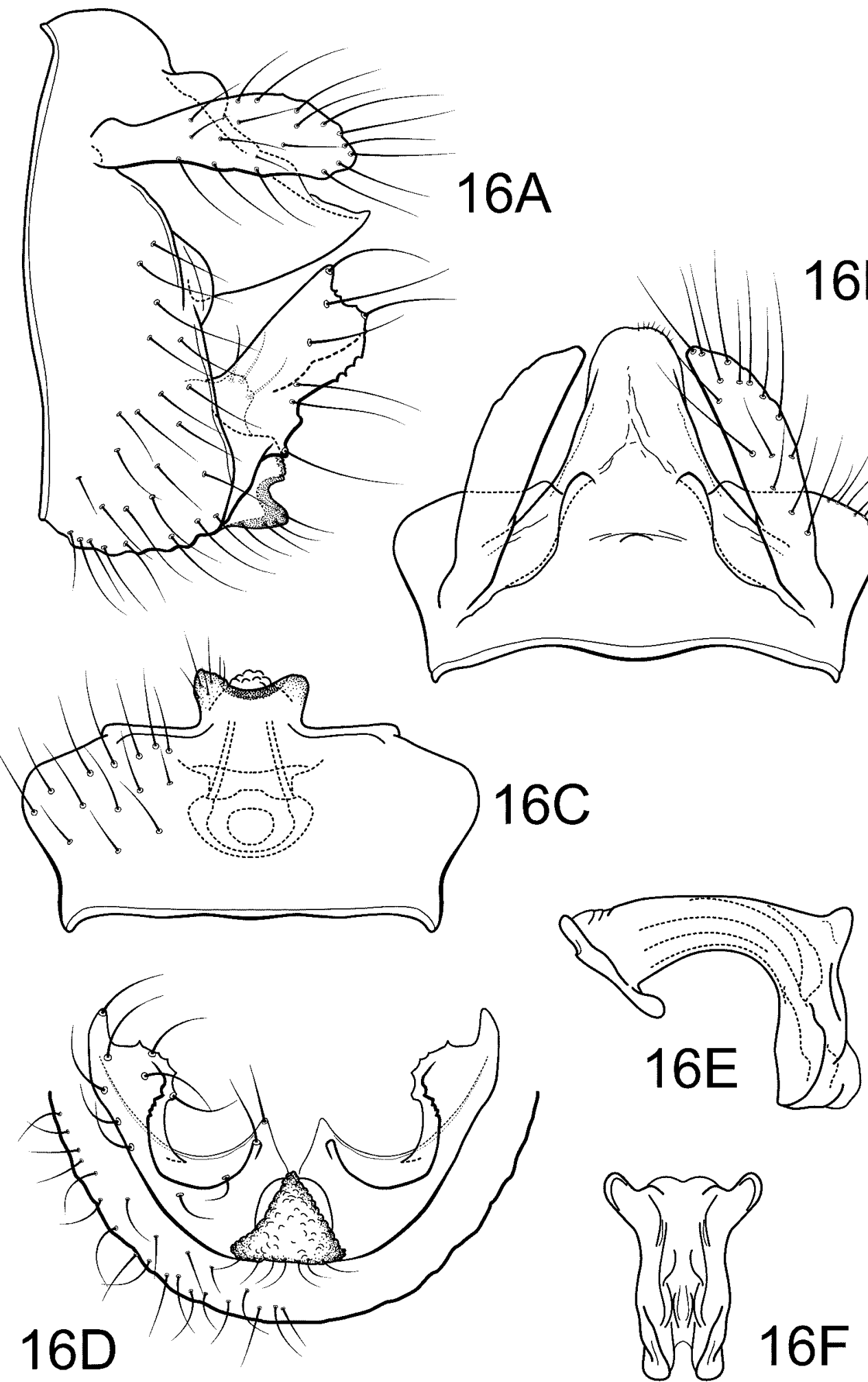

FIGURE 16. Tagalopsyche udagama, new species. Male genitalia: A—abdominal segments IX \& X, lateral; B-same, dorsal; C—abdominal segment IX, ventral; D—inferior appendages and process of sternum IX, caudal; E—phallic apparatus, lateral; $\mathrm{F}$ - same, caudal. 
Adult. Length of forewing: male 5.5-6.0 mm $(\mathrm{n}=3)$. Color dark brown, with scattered white hairs and small patches of white hairs.

Male. Abdominal segment IX annular, setose, especially ventrally; in lateral view anterior and posterior margins nearly parallel, shortest at insertion of preanal appendage; tergum IX broad; posterior extension of sternum IX short, less than 1/3 length of sternum, in ventral view base narrow, apex excised, overall shape quadrate, apical margin with shallow, U-shaped excision, apicolateral corners rugose, setose, in lateral view subtriangular; posterior process of segment IX extended dorsad to form heavily sclerotized projection, surface entirely rugose, in caudal view projection triangular, in lateral view subtruncate, in ventral view rounded, entire. Preanal appendage lanceolate, heavily setose, slightly shorter than segment X, apex subacute. Inferior appendage spatulate, setose, apex curved mesad, in lateral view subrectangular, dorsal and ventral edges nearly parallel, apicoventral edge irregularly rounded, mesolateral surface with irregular setose ridge, basoventrally without processes, mesobasally with subtriangular process bearing apical setae; dorsolaterally with pair of short, broad protuberances, in dorsal view apex rounded. Phallic apparatus short, compact; phallobase tubular, apparently fused with phallicata, basoventrally with short sclerotized flange apparently articulating with base of fused inferior appendages; phallicata strongly down turned apically at nearly 90 degrees to phallobase, apex of phallicata with irregular lateral sclerotized flanges and mesal membranous region, dorsolateral corners digitate, projecting; parameres absent; phallotremal sclerite not discernable.

Female. Unknown.

Holotype male: INDIA: Mysore: Anjadi, 23.i.1959, F. Schmid (CNC).

Paratypes: same data as holotype, — 2 males (CNC); INDIA: Kerala: Kalpatti, 13.i.1962, F. Schmid — 2 males (CNC). SRI LANKA: Galle: Udagama, Kanneliya Jungle, 6-12.x.1973, Malaise - 1 male (NMNH); Kandy: Hasalaka Irrigation Bungalow, 5 mi. NW Mahiyangana, 30.iii-9.iv.1971, P. \& P. Spangler, blacklight — 1 male (NMNH).

Distribution. India, Sri Lanka.

Etymology. Named for the locality in Sri Lanka, where the species was collected. The epithet is to be regarded as a noun in apposition.

\section{Fernandoschmidia, new genus}

Type species: Fernandoschmidia aramaniya, new species, original designation.

Other included species: F. amudita, new species.

Adult. Length of forewing: male $6.5 \mathrm{~mm}$, female 7.5-8.0 mm. Eyes not enlarged. Antennae long, 2-3X length of forewing in male; scape large, subspherical. Maxillary palps long, heavily setose; labial palps much shorter. Head anteromesal setal wart large, oval; anterolateral setal warts small, oval; posterolateral setal warts elongate oval. Tibial spurs $0,2,2$. Forewing narrow, apex subacutely rounded; with dense, short decumbent hairs on membrane, and with conspicuous, erect setae along veins; color brown, with scattered small patches of white hairs and distinct white spots at arculus, stigma, and apical wing margin. Forks I and V present in both wings; in forewing, thyridal cell about $2 \mathrm{X}$ as long as discoidal cell, fork I with short stalk; forewing anastomosis straight, veins not contiguous; in hind wing stem of $\mathrm{R}$ degenerate in type species, but this character not observed in unique holotype of second species; fork V long.

Male genitalia. Abdominal segment IX annular, setose, anterior and posterior margins parallel; tergum IX long, anterior margin with small acrotergites; sternum IX extended posteriorly, short, divided into pair of widely separated digitate processes. Preanal appendages lanceolate, heavily setose. Inferior appendages with broad, compact basal region and narrow digitate apical region; ventrolateral corner of basal region with flange-like, sclerotized ridge; apical region bifurcate apically. Tergum X saddle-shaped, short, in lateral view narrow, triangular, apex acute, dorsolaterally with pair of low, weakly developed protuberances. Phallic appa- 
ratus elongate; phallobase subspherical, only partially fused with phallicata, with ridge-like flange articulating with dorsolateral corners of basal region of interior appendages; phallicata gradually curved ventrad along its length, apex slightly expanded, with apicomesal membranes; parameres long, heavily sclerotized, bearing numerous thick spines; phallotremal sclerite not discernable.

Female genitalia. Only known for $F$. aramaniya, new species; see description.

Distribution. India.

Etymology. The genus is named in honor of the late Dr. Fernand Schmid in recognition of his monumental contributions to world Trichopterology.

\section{Fernandoschmidia amudita, new species}

Fig. 17

This and the following new species can be separated most readily on characters of the inferior appendage and phallic apparatus. In F. amudita the apical forks of the inferior appendage are subequal while in $F$. aramaniya, new species, the dorsal fork is much shorter than the ventral. In $F$. amudita the parameres are very long and relatively straight while in F. aramaniya they are shorter and curved. The dorsal keel on the phallicata is much larger and wider in F. amudita and there is a subapical ventral spine-like projection on the phallicata not seen in F. aramaniya.

Adult. Length of forewing: male $6.5 \mathrm{~mm}(\mathrm{n}=1)$. Color brown, with scattered small patches of white hairs and distinct white spots at arculus, stigma, and apical wing margin.

Male. Abdominal segment IX annular, setose, especially ventrally; in lateral view anterior and posterior margins parallel; tergum IX long; anterior margin with pair of small acrotergites; posterior extension of sternum IX short, 1/2 length of sternum, in ventral view divided into pair of widely separated digitate processes, apices subacute, in lateral view digitate, tapering to acute apex. Preanal appendage lanceolate, heavily setose, about as long as segment $\mathrm{X}$, apex acute, slightly directed mesad. Inferior appendage with broad, compact basal region and narrow digitate apical region, ventrolateral corner of basal region with subtruncate, flangelike, sclerotized ridge (best seen in caudal view), apical region bifurcate apically, dorsal fork short, narrowly digitate, ventral fork long, narrow. Tergum X saddle-shaped, short, about $1 / 3$ width of segment IX, in lateral view triangular, apex acute, dorsolaterally with pair of low, weakly developed protuberances, in dorsal view apex slightly emarginate. Phallic apparatus elongate; phallobase subspherical, only partially fused with phallicata; phallobase ventrolaterally with ridge-like flange articulating with dorsolateral corners of basal region of inferior appendages; phallicata gradually curved ventrad along its length, apex of phallicata bulbous, with subapical, spine-like projection and apicomesal membranes; dorsally with large, rounded, medial keel; parameres very long, heavily sclerotized, relatively straight, bearing numerous thick spines apically; phallotremal sclerite not discernable.

Female. Unknown.

Holotype male: INDIA: Assam (Kameng), Bhairabkunda, 3-4, 7.iii.1961, F. Schmid (CNC).

Distribution. India.

Etymology. This Sanskrit name was used by Schmid. We could not find an exact translation, but as a part of some words it may pertain to happiness or joy. The epithet is to be regarded as a noun in apposition.

\section{Fernandoschmidia aramaniya, new species}

Figs. 18-20

Characters to separate this new species from $F$. amudita are discussed under the diagnosis of that species. 


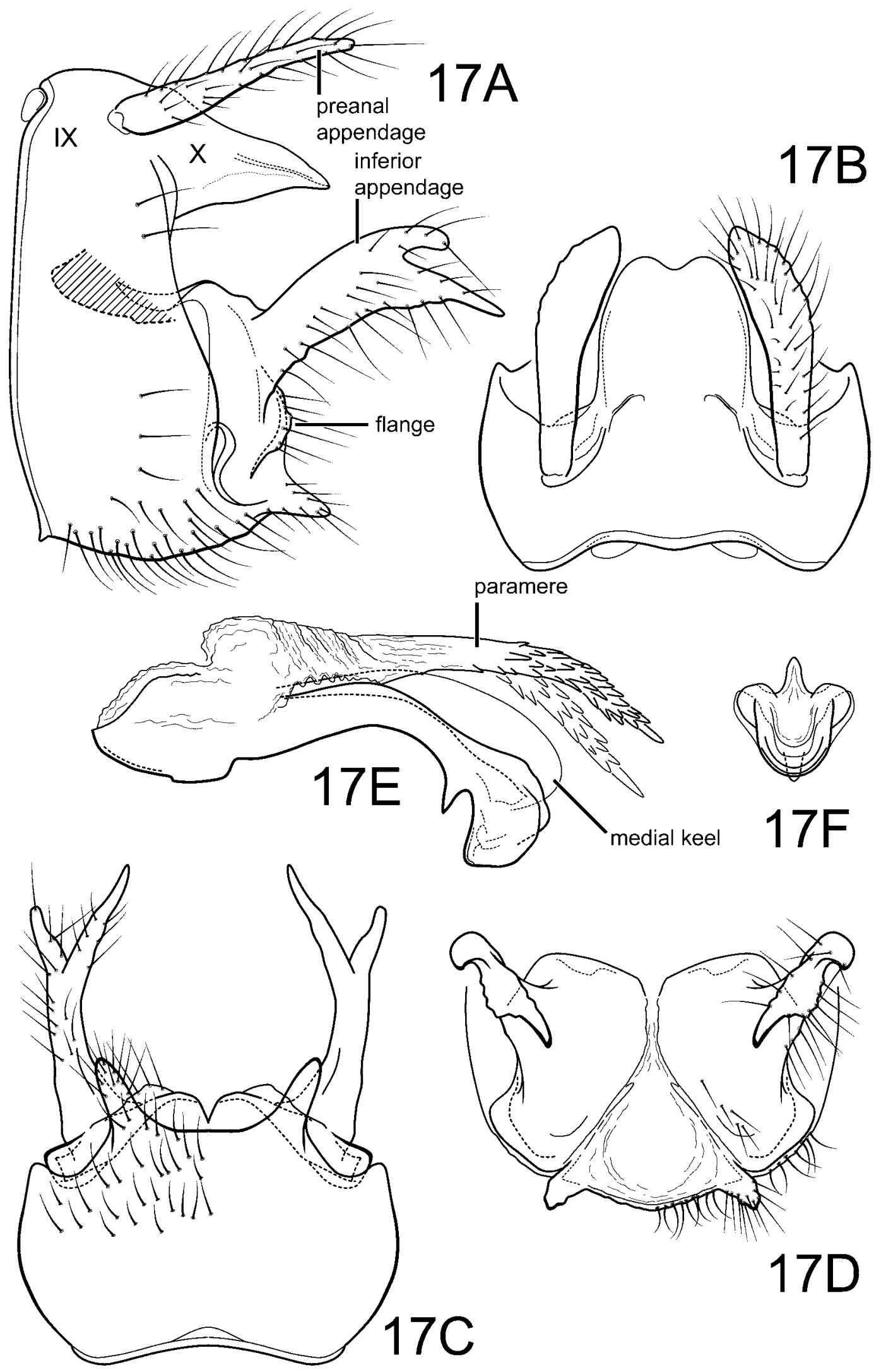

FIGURE 17. Fernandoschmidia amudita, new species. Male genitalia: A-abdominal segments IX \& X, lateral; Bsame, dorsal; C-abdominal segment IX, ventral; D—inferior appendages, caudal; E-phallic apparatus, lateral; Fapex of phallicata, caudal. 
Adult. Length of forewing: male $6.5 \mathrm{~mm}(\mathrm{n}=3)$, female 7.5-8.0 $(\mathrm{n}=2)$. Color brown, with scattered small patches of white hairs and distinct white spots at arculus, stigma, and apical wing margin; female coloration as in male, but patches and spots cream colored.

Male. Abdominal segment IX annular, setose, especially ventrally; in lateral view anterior and posterior margins parallel; tergum IX long; anterior margin with pair of small acrotergites; posterior extension of sternum IX short, 1/2 length of sternum, in ventral view divided into pair of widely separated digitate processes, apices rounded, in lateral view digitate, tapering to acute apex. Preanal appendage oblanceolate, heavily setose, longer than segment $\mathrm{X}$, apex acute, slightly directed mesad. Inferior appendage with broad, compact basal region and narrow digitate apical region, ventrolateral corner of basal region with rounded, flange-like, sclerotized ridge (best seen in caudal view), apical region bifurcate apically, dorsal fork very short, broadly digitate, ventral fork short, very narrow. Tergum X saddle-shaped, short, about 1/3 width of segment IX, in lateral view triangular, apex acute, dorsolaterally with pair of low, weakly developed protuberances, in dorsal view apex slightly emarginate. Phallic apparatus elongate; phallobase subspherical, only partially fused with phallicata; phallobase ventrolaterally with ridge-like flange articulating with dorsolateral corners of basal region of inferior appendages; phallicata gradually curved ventrad along its length, apex of phallicata slightly expanded, with apicomesal membranes; dorsally with low medial keel; parameres long, heavily sclerotized, curved, bearing numerous thick spines mesally and apically; phallotremal sclerite not discernable.
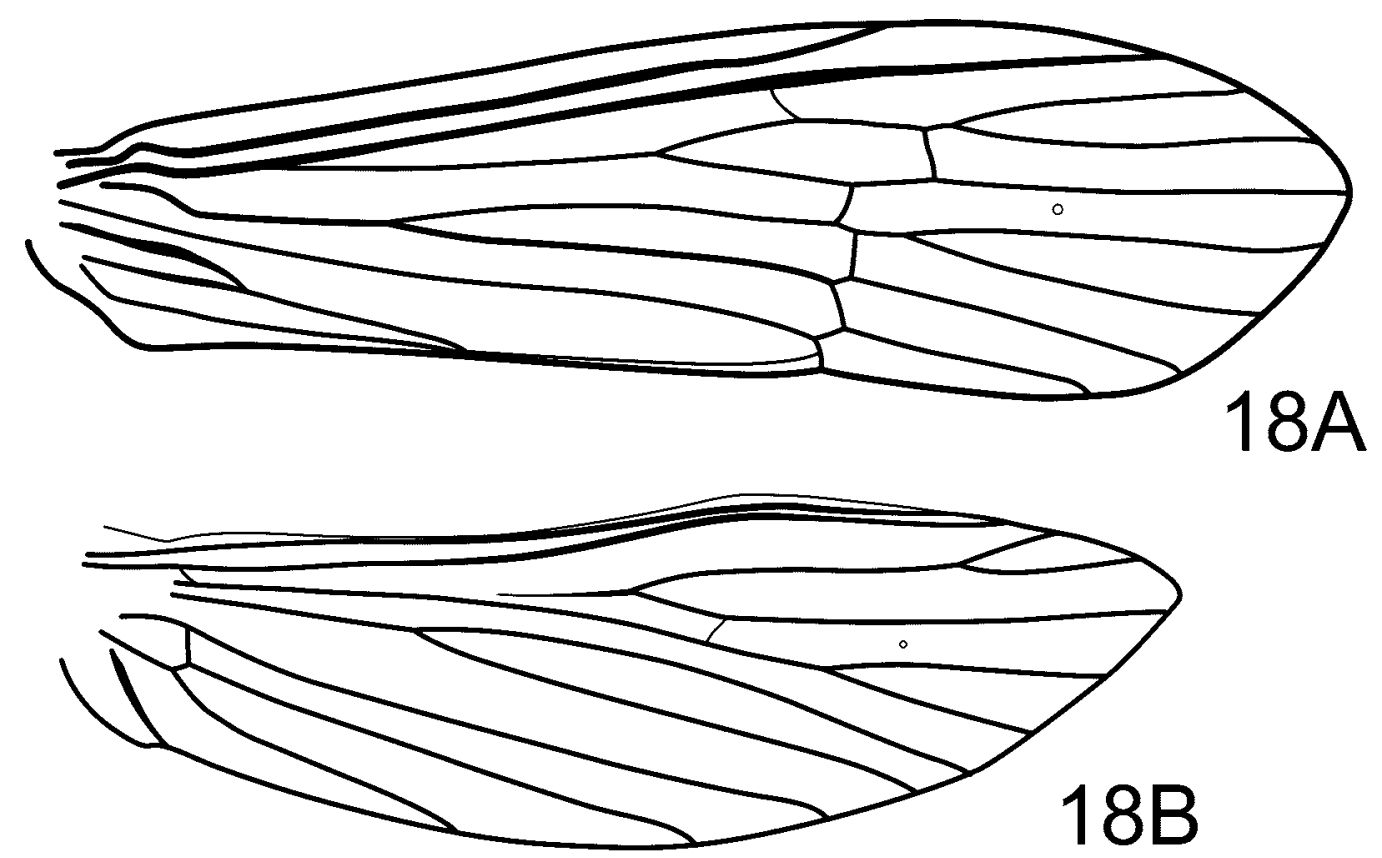

FIGURE 18. Fernandoschmidia aramaniya, new species. Wings: A—forewing; B—hind wing.

Female. Segment IX short, in lateral view posterior margin slightly rounded, anteroventral margin sinuous. Tergum X long, almost as long as preanal appendages, in lateral view triangular, apex subacute, in dorsal view broadly rounded, surface with crescentric striae; basolaterally without papillate processes. Preanal appendage long, digitate, setose. Lamella very large, very narrowly constricted basally, in lateral view directed ventrad, dorsal margin broadly rounded, ventral margin straight, apex rounded, outer and inner surfaces setose; in ventral view lamella straight, mesal surface concave. Gonopod plate basolateral edges produced in flanges, apex with very slight excavation, surface with fine striation. Spermathecal sclerite complex, in ventral view oval, apex subacute, laterally with semimembranous flanges, medially with keyhole-shaped sclerite.

Holotype male: INDIA: (U.J.K.H.) [Assam, United Khasi-Jaintia Hills District] Demthring, 16.iv.1960, F. Schmid (CNC). 
Paratypes: INDIA: (U.J.K.H.) [Assam, United Khasi-Jaintia Hills District] Thangrain, 22.iv.1960, F. Schmid -2 males (CNC); same data as holotype -2 females (CNC).

Distribution. India.

Etymology. This Sanskrit name was used by Schmid. We could not find an exact translation, but as a part of some words it may pertain to pleasant or delightful. The epithet is to be regarded as a noun in apposition.

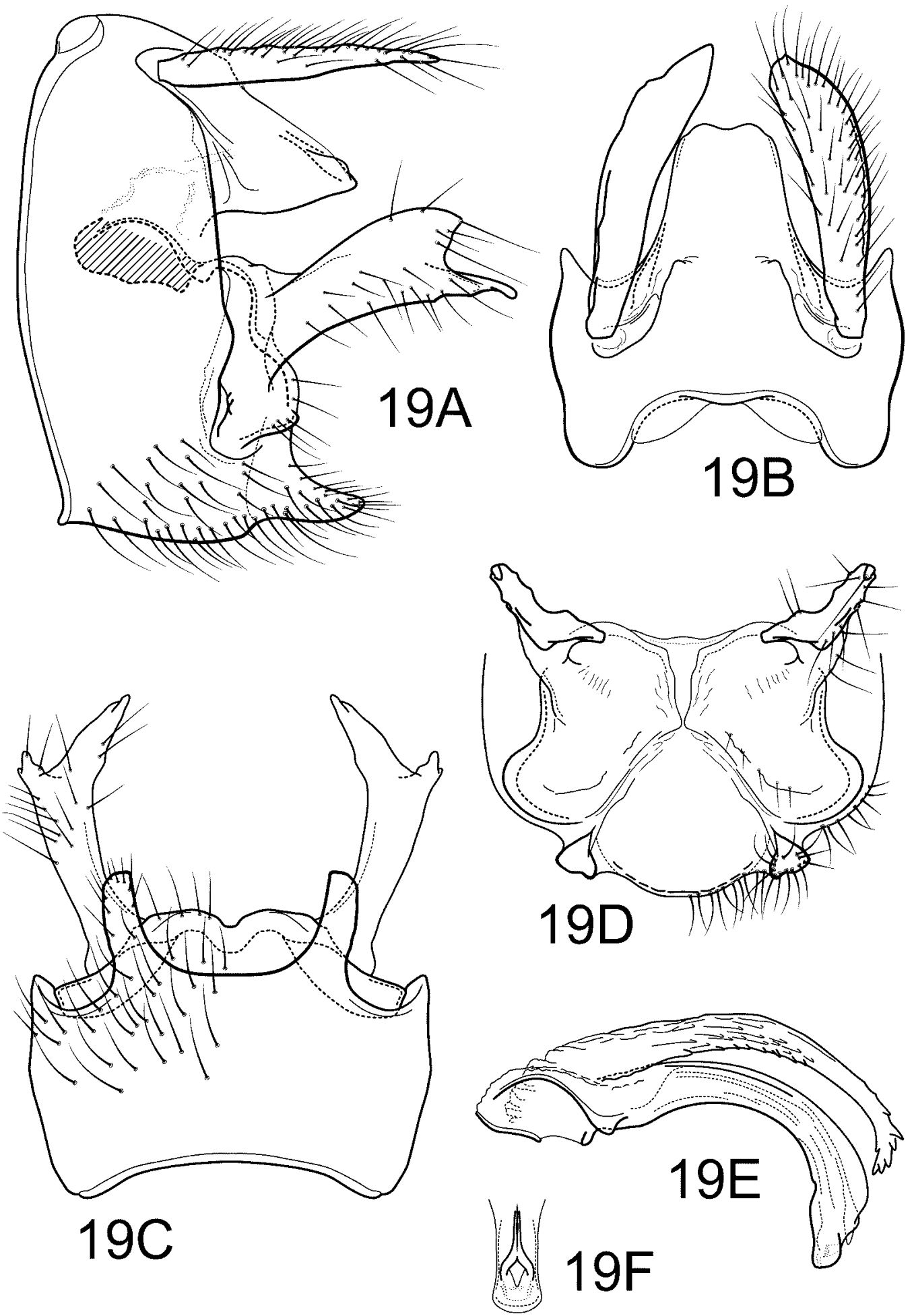

FIGURE 19. Fernandoschmidia aramaniya, new species. Male genitalia: A—abdominal segments IX \& X, lateral; Bsame, dorsal; C—abdominal segment IX, ventral; D—inferior appendages, caudal; E—phallic apparatus, lateral; Fapex of phallicata, caudal. 

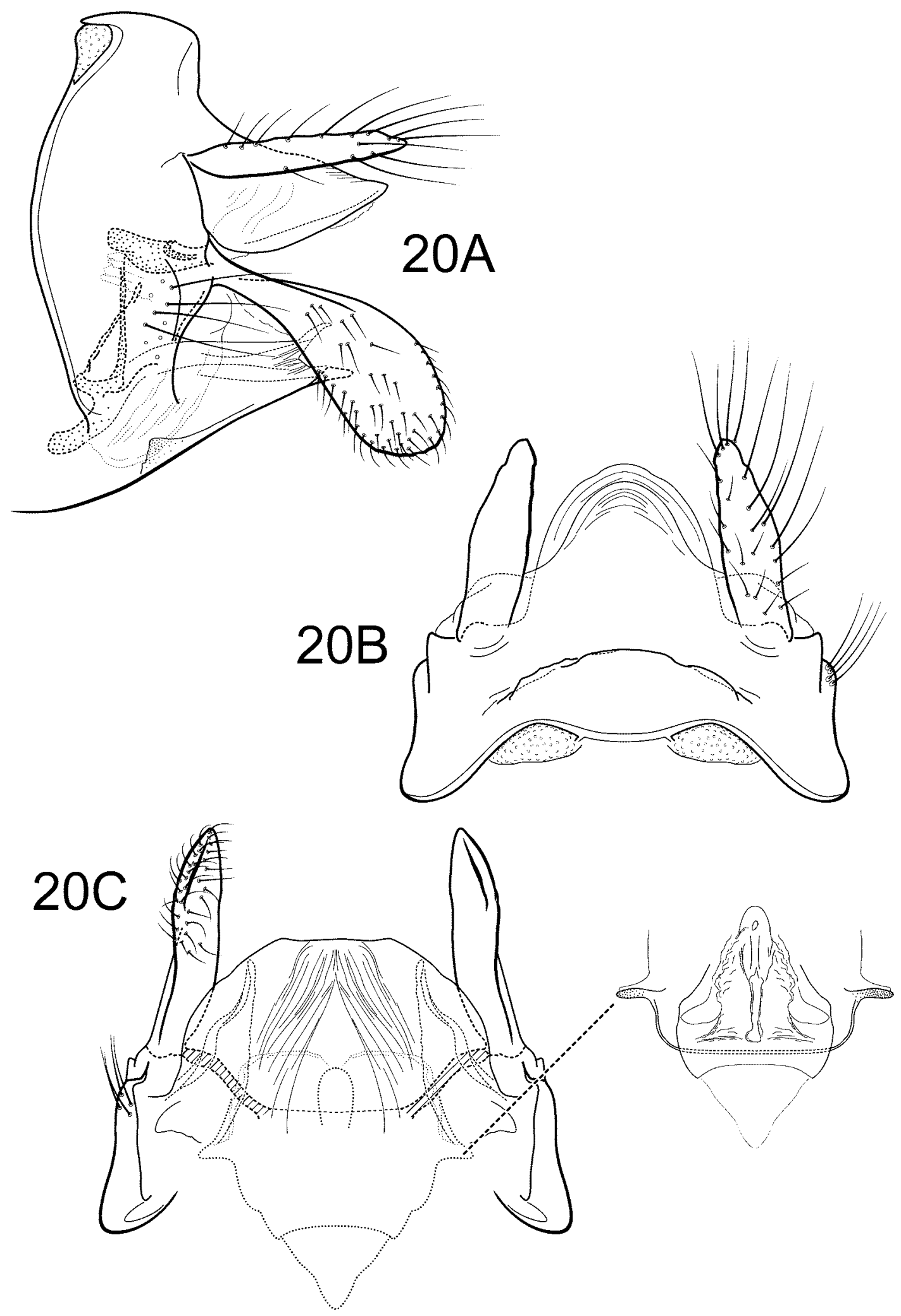

FIGURE 20. Fernandoschmidia aramaniya, new species. Female genitalia: A—abdominal segments IX \& X, lateral; B-same, dorsal; C—same, ventral (inset: spermathecal sclerite complex). 


\section{Acknowledgments}

The project in Ghana was funded by the Norwegian Universities' Committee for Development, Research and Education (NUFU). We are indebted to the staff at the participating institutions, particularly Joseph S. Amakye, Institute of Aquatic Biology, Accra, and Jostein Kjærandsen, Zoologiska Museet, Lund, Sweden. We are grateful to Jolanda Huisman for making the material from Malaysia available to us. We also extend our sincere appreciation to Oliver S. Flint, Jr., (NMNH), Jan van Tol (RMNH), David Goodger (NHM), Ian Smith (CNC), and H. Strümpel (ZSZMH) for providing types and other important material for incorporation in this study. Roger Blahnik, University of Minnesota, read an early draft of the manuscript and made many useful suggestions. This material is based upon work supported by the National Science Foundation grant nos. DEB $9971885 \& 0117772$.

\section{References}

Andersen, T., \& Holzenthal, R.W. (2001) West African Triaenodes McLachlan (Trichoptera: Leptoceridae). 1. Subgenus Triaenodella. Tijdschrift voor Entomologie, 144, 225-246.

Andersen, T., \& Holzenthal, R.W. (2002a) West African Adicella McLachlan, 1877 (Trichoptera: Leptoceridae). In: Mey, W. (Ed.), Proceedings of the 10th International Symposium on Trichoptera. Nova Supplementa Entomologica, Keltern, 15, 88-95.

Andersen, T., \& Holzenthal, R.W. (2002b) West African Triaenodes McLachlan (Trichoptera: Leptoceridae). 2. Subgenus Triaenodes sensu stricto. Tijdschrift voor Entomologie, 145, 61-88.

Andersen, T., \& Kjærandsen, J. (2001) Adult caddisfly diversity along a headwater stream in south-eastern Ghana (Insecta: Trichoptera). Verhandlungen für die Internationale Vereinung für Theoretische und Angewandte Limnologie, 27; 3613-3618.

Banks, N. (1913) On a collection of Neuropteroid insects from the Philippine Islands. Proceedings of the Entomological Society of Washington, 15, 170-180.

Banks, N. (1916) Neuropteroid insects of the Philippine Islands. Philippine Journal of Science, 11, 195-217.

Berthold, A.A. (1827) Latreille's Natürliche Familien des Thierreichs met Ammerkungen und Zusätzen. Volume 8. 602 pp. Weimer.

Blahnik, R.J., \& Holzenthal, R.W. (2004) Collection and curation of Trichoptera, with an emphasis on pinned material. Nectopsyche, Neotropical Trichopera Newletter, 1, 8-20. Available from http://www.entomology.umn.edu/museum/ links/news.html (accessed 25 January 2007).

Holzenthal, R.W., \& Andersen, T. (2004) The genus Triaenodes in the Neotropics (Trichoptera: Leptoceridae). Zootaxa, $511,1-80$.

Kimmins, D.E. (1963a) On the Trichoptera of Ethiopia. Bulletin of the British Museum (Natural History) Entomology, 13, 119-170.

Kimmins, D.E. (1963b) On the Leptocerinae of the Indian sub-continent and North East Burma (Trichoptera). Bulletin of the British Museum (Natural History) Entomology, 14, 263-316.

Morse, J.C. (1981) A phylogeny and classification of family-group taxa of Leptoceridae (Trichoptera). In: Moretti, G.P. (Ed.), Proceedings of the 3rd International Symposium on Trichoptera. Dr. W. Junk Publishers, The Hague, pp. 257263.

Morse, J.C., \& Yang, L. (2002) Phylogeny, classification, and historical biogeography of world species of Mystacides (Trichoptera: Leptoceridae), with a new species from Sri Lanka. In: Mey, W. (Ed.), Proceedings of the 10th International Symposium on Trichoptera. Nova Supplementa Entomologica, Keltern, 15, 173-186.

Ulmer, G. (1905) Trichopteren aus Java. Mitteilungen aus dem Naturhistorischen Museum Hamburg, 22, 89-100.

Ulmer, G. (1906) Neuer beitrag zur kenntnis aussereuropaeischer Trichopteren. Notes from the Leyden Museum, 28, 1116.

Ulmer, G. (1907a) Neue Trichopteren. Notes from the Leyden Museum, 29, 1-53.

Ulmer, G. (1907b) Trichoptera. In: Wytsman, P. (Ed.), Genera Insectorum, Vol. 60, 1-259.

Ulmer, G. (1913) Über einige von Edw. Jacobson auf Java gesammelte Trichopteren, Zweiter Beitrag. Notes from the Leyden Museum, 35, 78-101.

Ulmer, G. (1930) Trichopteren von den Philippinen und den Sunda-Inseln. Treubia, 11, 373-498.

Ulmer, G. (1951) Köcherfliegen (Trichoptera) von den Sunda-Inseln. Teil I. Archiv für Hydrobiologie, Supplement, 19, $1-528$. 
Ulmer, G. (1955) Köcherfliegen (Trichoptera) von den Sunda-Inseln. Teil II. Archiv für Hydrobiologie, Supplement, 21, 408-608.

Ulmer, G. (1957) Köcherfliegen (Trichoptera) von den Sunda-Inseln. Teil III. Archiv für Hydrobiologie, Supplement, 23, 257-271.

Weidner, H. (1964) Die Entomologischen Sammlungen des Zoologischen Staatsinstituts und Zoologischens Museums Hamburg X Teil, Insecta VII. Mitteilungen aus dem Hamburgischen Zoologischen Museum und Institut, 62, 55-100.

\section{Note added in proof}

After this paper went to press, a paper by H. Malicky was published on 29 December 2006 describing 2 new species from Thailand, Tagalopsyche osiris Malicky \& Prommi and Tagalopsyche orpheus Malicky \& Chantaramongkol, and including the synonymy of Tagalopsyche fletcheri Kimmins 1963 with Tagalopsyche brunnea (Ulmer 1905).

Malicky, H. (2006) Beiträge zur Kenntnis asiatischer Leptoceridae (Trichoptera: Adicella, Athripsodes, Ceraclea, Leptocerus, Oecetis, Parasetodes, Tagalospyche, Triaenodes, Trichosetodes). Linzer Biologischen Beiträgen, 38, 15071530. 